\title{
Über die Todesursache bei innerer Verblutung infolge von Leberverletzung.
}

\author{
Von \\ Isamu Shinohara. \\ (䈩 原画) \\ (Aus dem Institut fïr Gerichtsmedizin an der Kaiserlichen \\ Tohoku-Universität. Direktor: Prof. Dr. T. Ishikavva.)
}

I. Einleitung.

II. Versuchsmethode.

III. Experimentelle Ergebnisse.

1. Kontrollversuche.

(a) Einfluss wiederholter Blutuntersuchungen. (b) Einfluss intraperitonealer Infusion physiologischer Kochsalzlösung. (c) Verlauf der natürlichen Besserung auf Aderlass beruhender Blutarmut. (d) Einfluss der Probelaparotomie.

2. Vorversuche.

\section{Inhaltsverzeichnis.}

(a) Intraperitoneale Infusion artgleichen Erythrozytenbreis bei gesunden Kaninchen. (b) Intraperitoneale Infusion ihres eigenen Erythrozstenbreis bei durch Aderlass blutarm gewordenen Kaninchen. (c) Intraperitoneale Infusion teilweise hämolysierten Ergthrozgtenbreis bei gesunden Kaninchen. (d) Intraperitoneale Infusion teilweise hämolysierten Erythrozytenbreis bei durch Aderlass anämisch gewordenen Kaninchen. (e) Intraperitoneale Infusion mit Galle gemischten Erythrozytenbreis bei gesunden Kaninchen. (f) Intraperitoneale Infusion mit Leberbrei gemischten Erythrozytenbreis bei gesunden Kaninchen. (g) Intraperitoneale Infusion mit Milzbrei gemischten Erythrozytenbreis bei gesunden Kaninchen.

3. Hanptversuche.

(a) Innere Verblutung bei Leberquetschung. (b) Innere Verblutung bei Milzquetsehung.

IV. Zusammenfassung.

V. Sehluss.

Literatur.

\section{Einleitung.}

Es ist schon allgemein anerkannt, dass beim Tod durch Verblutung meistens starke Anämie eintritt, die beim Tod durch innere Verblutung schwächer als bei dem durch äussere ist. Aber beim Tod 
durch intraperitoneale Blutung zeigt sich oft keine bedeutende Anämie, sodass man dabei die Todesursache nicht der inneren Blutung zuzuschreiben vermag und wagt, eine bei der gerichtsmedizinischen Sektion, besonders beim Tod durch Leberverletzung häufig zu beobachtende Tatsache. Bei solchem auf intraperitonealer Blutung beruhenden Tod hat man deshalb überhaupt vermutet, dass es sich dabei vielmehr um den sogenannten Autointoxikationstod handelt, der durch die Resorption irgendeines Gifts hervorgerufen wurde, das in dem in der Bauchhöhle vorhandenen Blut selbst erzeugt ward. Aber die Todesursache bei solchen Fällen ist damit noch nicht gek]ärt. Schon viele Forscher haben den Verbleib des in die Bauchhöhle ausgeflossenen Bluts und dessen Wirkung auf den lebenden Körper je nach ihrem Standpunkt beurteilt. Voge ${ }^{1)}$ stellte experimentell fest, dass bei Kaninchen das intraperitoneal eingespritzte Blut vollkommen resorbiert wurde und Irokawa, ${ }^{2)}$ dass solches Blut im Verlauf von $\frac{1}{2}-2$ Tagen fast vollkommen resorbiert wurde. Was seine Wirkung auf den lebenden Körper betrifft, so meinten $\mathrm{Br}$ ö se $\mathrm{e}^{3)}$ und Löwenste in, ${ }^{4)}$ dass sein weiteres Verbleiben in der Bauchhöhle sehr gefährlich werde, und sahen diese Gefahr in der bakteriellen Infektion oder der Giftigkeit der Zerfallprodukte des einverleibten Bluts. Aber Mackenrodt $t^{5}$ und Franz $\mathrm{z}^{(j)}$ bestritten dies und behaupteten, dass das intraperitoneal ausgeflossene Blut im Gegenteil vorteilhaft wirke. Quincke $\mathrm{e}^{i}$ ermittelte, dass durch intraperitoneale Infusion frischen, defibrinierten, homogenen Bluts bei einem Kaninchen Eisenablagerung in seinen Organen und seinem Knochenmark und Polyzythämie auftraten. Weiter meinte Irok awa, Infusion einer grossen Menge von Blut könne leicht experimentelle Polyzythämie hervorrufen, was aber wahrscheinlich nur die günstige Wirkung der intraperitonealen Blutinfusion auf die Empfangstiere bestätigt. Aus allen diesen Urteilen kann man also die eigentliche Todesursache bei intraperitonealer Verblutung durchaus noch nicht ersehen. Aber Takizawa $a^{8)}$ gab an, dass bei Kaninchen intraperitoneale Infusion teilweise hämolysierten, homogenen Bluts auf ihre Plasmakatalase vermehrend wirke, und dass das hämolysierte Blut auf die Blutkörperchen des Empfangstiers zersetzend wirke. Weiter ermittelte er, dass bei Kaninchen die Plasmakatalase infolge der Unterbindung des Ductus choledochus zunahn, und schrieb dies der Auflösung der roten Blutkörperchen zu, die durch Einfliessen von Galle in den Blutkreislauf hervorgerufen wurde. Kürzlich hat Ishizaw a aus unserem Institut berichtet, dass Einverleibung einer Hämoglobinlösung auf die homogenen kreisenden Blut- 
körperchen auflösend wirken kann und dadurch sehr giftig wird. Nach den experimentellen Ergebnissen dieser beiden Forscher kann man auch vermuten, dass der Tod durch intraperitoneale Verblutung nicht nur auf dem Blutverlust beruht, sondern auch auf der Giftigkeit des hämolysierten Bluts, das durch irgendeine die Erythrozyten zersetzende Funktion erzeugt und dann wieder in die Zirkulation resorbiert worden ist.

Um die Todesursache bei intraperitonealer Verblutung experimentell zu ergründen, habe ich nun teils gesunden, teils durch Aderlass anämisch gemachten Kaninchen Erythrozytenbrei oder mit hämolysiertem Blut gemischten oder eine Mischung von Erythrozytenund Organbrei intraperitoneal eingeflösst oder innere Verblutung dụrch Quetschung eines Bauchorgans, besonders der Leber, eintreten lassen. Danach habe ich die Wirkung jedes einzelnen transfundierten oder selbst ergossenen Bluts auf den lebenden Körper beobachtet. Ich habe dabei Vorhandensein der Hämolyse im Kreislauf vorzüglich nach der Plasmakatalase bestimmt, weil ich die kürzlich mitgeteilte Angabe Kurokawa s $^{13}$ anerkenne. Denn er meinte, dass die Menge der Katalase im Blutplasma des gesunden Kaninchens fast immer konstant sei und durch Blutentnahme oder intraperitoneale Blutinfusion nebst Blutentriahme nicht ins Schwanken komme, sondern entweder durch infolge von Injektion destillierten Wassers oder Galle hervorgerufene intravaskuläre Hämolyse oder durch eine mechanische oder pharmakologische Störung der Leber besonders stark zunehme, während Becht, ${ }^{9)}$ Van Thienen, ${ }^{10)}$ Oppenheimer ${ }^{11)}$ und $\mathrm{Ochi}{ }^{123}$ behaupten, dass Plasma und Serum keine Katalase enthalten und Spuren davon nur deshalb erscheinen, weil die Zelltrümmer noch nicht beseitigtet sind.

Meine Versuche habe ich nach folgendem Plan ausgeführt: zur Kontrolle und experimentellen Grundlegung habe ich zuerst bei den Versuchstieren die auf experimentellem oder operativem Eingrift' beruhenden Veränderungen beobachtet und dann bald den normalen, bald den anämisch gemachten Versuchstieren in die Bauchlöhle 1) Erythrozytenbrei, 2) mit hämolysiertem Blut gemischten Erythrozytenbrei, 3) mit Galle gemischten Erythrozytenbrei oder 4) eine mit Erythrozyten- und Organbrei gemischte Lösung injizier't und zuletzt durch Quetschung eines intraperitonealen Organs innere Verblutung hervorgebracht, woraufhin ich verschiedene Blutbilder, Plasmakatalase und die Zahl und die Resistenz der Erythrozyten festgestellt habe. Aus der Abnahme der Erythrozytenzahl kann man das Vorhandensein 
der Hämolyse erkennen und aus der Veränderung der Erythrozytenresistenz die Resorption des hämolysierten Bluts in den Kreislauf.

\section{Versuchsmethode.}

(1) Als Versuchstiere habe ich über $2 \mathrm{~kg}$ schwere, gesunde Kaniuchen benutzt. Vor dem Versuch wurden sie mehrere Tage an einem bestimmten Ort mit bestimmter Nahrung gefüttert, damit sie sich an die Lage gewöhnten. Dann wurde jedes Kaninchen noch vor dem Versuch zweimal untersucht, wobei der Normalwert jeder Einzelheit bestimnt wurde.

(2) Bereitung des Erythrozy tenbreis.

Zur Herstellung des zu benutzenden Erythrozytenbreis liess ich zuerst das Blut aus der Ohrvene des Kaninchens durch einen Stich mit einer Injektionsnadel tröpfeln und tat davon die erforderliche Menge in ein eingeteiltes Spitzglas, das $0,5 \%$ Na-Zitrat in physiologischer Kochsalzlösung enthielt. Nach dem durch Zentrifugierung (2000 Umdrehungen in der Minute) geschaffenen Niederschlag entfernte ich die obere Schicht möglichst vollständig und sog mit einer Pipette die die Erythrozytenschicht als dünne, graufarbige Schicht bedeckenden Leukozyten und Blutplättchen rollkommen fort. Der Rest wurde mit sterilisierter physiologischer Kochsalzlösung gemischt und zentrifugiert. Auf diese Weise wurden die Blutkörperchen dreimal gewaschen, sodass die Erythrozyten fast rein abgesondert werden komnten. Zur Infusion fügte ich wieder physiologische Kochsalzlösung hinzu, bis die anfüngliche Blutmenge wieder erreicht war.

(3) Bestimmung der Katalase.

Zur Bestimmung der Plasmakatalase folgte ich der Methode Ku roka was; die Ziffern in den Tabellen stellen die Menge der N/50 Thiosulfatlösung dar. Die Blutkatalase wurde nach Inoues Methode (bei mit Fleischl-Miescher-Melangeur 400 fach verdünnter Blutlösung) durch N/50 Kaliumpermanganatlösung: titriert; die in den Tabellen den Katalasegehalt wiedergebenden Ziffern sind mit dem Index von Inoue multiplizierte Zahlen, und den Blutkatalaseindex zeigt der Quotient an, der sich durch Division des Blutkatalasegehalts mit der Millionenzahl der Erythrozyten ergibt.

(4) Bestimmung der osmotischen Resistenz roter Blutkörperchen.

Zur Bestimmung der osmotischen Resistenz roter Bhtkörperchen gegen hypotonische Kochsalzlösung benutzte ich das Kochsalz und folgte der Methode von Hamburger u. Limbeck, und zur Messung beobachtete ich die Maximalresistenz makroskopisch sowie mikroskopisch.

(5) Blutuntersuchungsmethode.

Das Blut wurde immer der Ohrvene entnommen und für dasselbe Versuchstier stets derselbe Melangeur benutzt. Zur Berechnung der Erythrozytenzahl wurde das Blut mit Hay emscher Lösung und zu der der Leukozytenzahl mit Türkscher Lösung verdünnt, und für die Erythrozyten sowie die Leukozyten wurde immer ein und derselbe Thoma-Z iss-Blutkörperchenzählapparat benutzt. Zur Bestimmung des Hämoglobingehalts benutzte ich immer einen 
Fleischl-Miescher-Melangeur. Zur Vorbereitung der Blutstrichpräparate strich ich das Blut auf das Objektglas und führte dann die Doppelfärbung von Oppenheim aus. Zur differentialen Zählung der Leukozyten zählte ich die Gesamtzahl der Leukozyten, falls die Lenkozy tenzahl fast normal war, bis über 300 und, falls sich starke Leukozytose zeigte, bis über 500, wonach der Prozentsatz jedes einzelnen Leukozytenbildes berechnet wurde.

\section{Experimentelle Ergebnisse.}

(1) Kontrollversuche.

(a) Einfluss wiederholter Blutuntersuchungen.

Zur Feststellung des Einflusses wiederholter Blutuntersuchungen stellte ich Versuche mit 2 Kaninchen an. Diese Ergebnisse sind in Tabelle 1 wiedergegeben. Bei der etwa im Verlauf einer Woche wiederholten Untersuchung waren die Erythrozytenzahl, der Hämoglobingehalt sowie der Hämoglobinindex gar nicht stark verändert, und die Leukozytenzahl schwankte zeitlich auch nur sehr wenig, ebenso schien der Gehalt der Blut- und Plasmakatalase bei jedem Individuum fast immer konstant zu sein. Die Resistenz der roten Blutkörperchen war auch nicht verändert, nur beim Prozentsatz der Leukozyten nahmen die pseudoeosinophilen Leukozyten etwas zu, im Gegensatz zur Abnahme der Lymphozytenzahl. Auch $\mathrm{Yag}^{\left.\mathrm{i}^{15}\right)}$ und $\mathrm{Hasu}$ i$\mathrm{ke},{ }^{16)}$ die noch länger als ich die Blutbilder des Kaninchens wiederholt beobachteten, bekamen die gleichen Ergebnisse wie ich; denn nach ihrem Bericht besteht bei gesunden Kaninchen unter den Blutbildern der einzelnen Individuen ein grosser Unterschied, aber bei ein und demselben Individuum seien die physiologischen und zeitlichen Schwankungen gar nicht bedeutend. Aus meinen experimontellen Ergebnissen und obigen Mitteilungen ist zu ersehen, dass von einem Einfluss wiederholter Blutuntersuchungen keine Rede sein kann.

(b) Einfluss intraperitonealer Infusion physiologischer Kochsalzlösung.

Bei der Infusion mit Erythrozytenbrei aufgeschwemmter physiologischer Kochsalzlösung muss man zunächst den Einfluss reiner physiologischer Kochsalzlösung untersuchen. 2 Kaninchen flösste ich darum $20 \mathrm{ccm}$ physiologischer Kochsalzlösung pro kg Körpergewicht in die Bauchhöhle ein. Wie Tabelle 2 zeigt, war nur eine leichte, auf der Zunahme pseudoeosinophiler Leukozyten beruhende Leukozytose nennenswert. Die Erythrozytenzahl nahm bei einem Fall nur am Tag 
nach der Infusion sehr wenig ab, schwankte dann aber um die Norm herum, ausserdem aber blieben der Hömoglobin- und Katalasegehalt sowie auch die Resistenz unverändert. Matsun $0^{17)}$ berichtete, dass bei Kaninchen intravenöse Infusion von $1 \mathrm{ccm}$ 0,85\% iger Kochsalzlösung pro kg weder auf die Leukozytenzahl noch auf die einzelnen Leukozytenbilder einwirkte, dass aber die Leukozytenzahl durch Infusion von $2 \mathrm{ccm}$ stark zunahm und nach 48 Stunden schon wieder ebenso wie vor der Infusion wurde. Taka mura ${ }^{18)}$ erhielt bei Kaninchen dieselben Ergebnisse, und Blueme ${ }^{19)}$ ermittelte bei Menschen nach intravenöser Infusion von 0,9\%iger Kochsalzlösung auch Leukozytose. Diese Mitteilungen beschränken sich alle auf die Ergebnisse nach intravenöser Infusion, teilen aber gar nichts über die nach intraperitonealer mit. Aber aus meinen Ergebnissen ist schon zu ersehen, dass die Wirkung intraperitonealer Infusion der der intravenösen fast gleich ist. Also erkannte ich, dass durch Infusion von $20 \mathrm{ccm}$ Kochsalzlösung pro $\mathrm{kg}$ keine andere nennenswert Veränderung als leicht Leukozytose hervorgerufen wird.

\section{(c) Verlauf der natürlichen Besserung durch Aderlass hervorgerufener Anämie.}

Den Ohrvenen zweier Kaninchen entnahm ich eine grosse Menge Blut und beobachtete die natürliche Besserung der Anämie, als Kontrolle für spätere Versuche. Als ich dem einen $15 \mathrm{ccm}$ Blut pro kg und dem anderen $20 \mathrm{ccm}$ pro $\mathrm{kg}$ entnommen hatte, bekamen beide sofort Anämie, und am Tag nach der Blutentnahme war die Abnahme der Erythrozytenzahl bei beiden Fällen am stärksten, und sie erforderte fast 2 Wochen zu ihrer Wiederherstellung. Die $\mathrm{Zu}$ oder Abnahme des Hämoglobingehalts ging mit der Erythrozytenzahl fast parallel, aber die Wiederherstellung war bei jenem etwas später als bei dieser, weshalb der Hämoglobinindex der Hauptsache nach unter 1 blieb. Die Leukozytenzahl neigte nach der Blutentnahme dazu, mehr oder weniger zuzunehmen, aber diese Zunahme war nur gering, und nach 4-5 Tagen wurde der Normalwert schon wieder erreicht. Die Blutkatalase begann, sofort nach der Blutentnahme, abzunehmen und erreichte ihren Minimalwert etwa zu gleicher Zeit, als die Erythrozytenzahl auch am kleinsten wurde. Dann nahm sie mit der Besserung der Anämie immer mehr zu und kehrte schon eine Woche früher als die Erythrozytenzahl wieder zum Normalwert zurück und neigte zu weiterer Zunahme, weshalb sich der Katalaseindex immer noch stärker erhöhte. Die Plasmakatalase wurde durch 
die Blutentnahme gar nicht beeinflusst. Die Resistenz der Erythrozyten begann erst ungefähr beim Einsetzen der Besserung der Anämie allmählich zu steigen, erreichte nach 5-6 Tagen ihr Maximum und war zur Zeit, da die Erythrozytenzahl schon wieder ihre Norm erreicht hatte, immer noch ziemlich hoch. Was das Blutbild betrifft, so nahmen nur pseudoeosinophile Leukozyten sichtlich zu, bei anderen Typen wurde kein Zusammenhang mit der Blutentnahme festgestellt. Als junge Formen traten eine grosse Anzahl polychromatophiler Erythrozyten mit Anisocytose und eine geringe Anzahl kernhaltiger Erythrozyten auf und beim einen Fall nur wenige basophile rote Blutkörperchen.

Nun möchte ich hier meine obigen experimentellen Ergebnisse mit denen einiger Vorgänger vergleichen. Hasuike und Lazar us ${ }^{20)}$ teilten mit, dass die maximale Abnahme der Erythrozytenzahl durch Entnahme einer grossen Menge Blut meistens am 2. Tage erfolge, und über ihre Rückkehr zur Norm berichteten Id o u. Su zu k i, ${ }^{11)} \mathrm{H}$ a suike und Yagi, dass sie mindestens 7-8 Tage, meistens aber 11-17 Tage erfordere, während die Wiederherstellung des Hämoglobingehalts im Vergleich zu der der Erythrozytenzahl etwas später eintrete. Die Mitteilungen von Milne ${ }^{22}$ und $\mathrm{Ochi}$ über den Hämoglobinindex, den sie als kleiner als 1 bestimmten, stimmen mit meinem betreffenden Ergebnis überein. Leukozytose wurde auch von Ido u. Suzuki und Rossius ${ }^{\text {(3) }}$ festgestellt, die erklärten, dass sie hauptsächlich auf der Zunahme pseudoeosinophiler Leukozyten beruhe und deren Vermehrung noch etwas länger als die der Leukozytenzahl dauere. Betreffs der Blutkatalase stimmte mein Ergebnis mit den Mitteilungen von Nozaki, ${ }^{44)} \mathrm{Kurokawa}$ und Ochi und betreffs der Plasmakatalase mit Kurokawas Ergebnis durch Entnahme einer grossen Menge Blut und mit Takizawas Ergebnis durch wiederholte Entnahme je einer kleinen Menge Blut völlig überein. Dass sich die Erythrozytenresistenz bei auf Blutentnahme beruhender Anämie erhöht, wurde schon von Itami u. Pratt, ${ }^{25}$ Snapper, ${ }^{9(2)}$ Sakai, ${ }^{27)}$ Swjatskaja, ${ }^{29)}$ Sattler, ${ }^{299}$ Schustroff, ${ }^{20)}$ Date, ${ }^{312} \mathrm{Oka}^{(22)}$ und Yamamoto $0^{332}$ mitgeteilt. AberViola u. Jona $\mathrm{a}^{34)}$ und Milne bestritten dies, die ersten beiden behaupteten im Gegenteil Senkung der Resistenz und der letzte ihre Unveränderlichkeit. Die Erhöhung der Resistenz in diesem Fall gilt aber heute fast als sicher. Alles dies zusammenfassend, gelangte ich zur Überzeugung, dass durch auf Blutentnahme beruhende Anämie die Plasmakatalase weder zu- noch abnimmt und die Besserung der Anämie etwa 2 Wo- 
chen erfordert und dass weiter die Resistenz der Erythrozyten dabei etwas zunimmt.

(d) Einfluss der Probelaparotomie.

Nach dem Festbinden des Kaninchens auf dem Operationstisch in Rückenlage öffnete ich durch einen unter streng aseptischen Kautelen ausgeführten, 4-5 cm langen Schnitt auf der-Medianlinie die Bauchhöhle und vernähte sie sofort wieder. Wie in Tabelle 4 wiedergegeben, wurden die Erythrozytenzahl, der Hämoglobingehalt, die Plasmakatalase und die Resistenz durch diese Laparotomie gar nicht verändert, es trat nur eine auf der Zunahme pseudoeosinophiler Leukozyten beruhende Leukozytose nach der Operation auf, und die Blutkatalase nahm gleich nach der Operation ein wenig zu. Diese meine Ergebnisse stimmen mit denen von Takiza wa und Date vollkommen überein (jener fand die Plasmakatalase und dieser die Resistenz unverändert) und weiter auch mit der Mitteilung Ottos, ${ }^{\text {;ij }}$ dass die Leukozytenzahl 24 Stunden nach der Operation ihr Maximum erreiche und nach 3-4 Tagen wieder zur Norm zurückkehre.

Als Einfluss der Probelaparotomie ermittelte ich also keine andere nennenswerte Veränderung als Leukozytose.

\section{Vorversuche.}

(a) Intraperitoneale Infusion artgleichen Erythrozytenbreis bei gesunden Kaninchen.

Die Ergebnisse intraperitonealer Infusion von $20 \mathrm{ccm}$ artgleichen Erythrozytenbreis pro kg bei 3 gesunden Kaninchen sind aus Tabelle 5 zu ersehen. Die Erythrozytenzahl begann schon gleich nach der Infusion stark zu steigen und erreichte bei jedem Fall entweder nach 1 Stunde oder am 2. Tage ihr Maximum, blieb dann noch einige Tage lang sehr hoch, kehrte aber binnen einer Woche wieder zum Normalwert zurück. Der Hämoglobingehalt ging mit der $\mathrm{Zu}$ - und Abnahme der Erythrozytenzahl parallel, und der Hämoglobinindex hielt sich meistens höher als 1. Die Zu- oder Abnahme der Leukozytenzahl war gleich nach der Infusion unbestimmbar, aber am 2. Tage war sie bei jedem Fall etwas vergrössert, erreichte jedoch am 3. Tage schon wieder die Norm. Mit dieser Veränderung der Leukozy tenzahl fast übereinstimmend, nimmt die absolute Menge der pseudoeosinophilen Leukozyten auch zu oder ab, und diese Zunahme verursacht hauptsächlich Leukozytose. Aber ihre relative Menge hängt nicht mit der $\mathrm{Zu}$ - 
oder Abnahme der Leukozytenzahl zusammen, weshalb sie immer gleich nach der Infusion stark zunahm und dann, allerdings verhältnismässig langsam, sank, aber meistens übermässig blieb. Die Plasmakatalase erfuhr keine als ungewöhnlich zu bezeichnende Zunahme, und die Blutkatalase behielt immer ihre Konstante. Die Resistenz roter Blutkörperchen verminderte sich wahrscheinlich nur etwas, was aber gar nicht bedeutend war.

Über die Veränderungen durch Infusion von Blutkörperchen wurde schon in der Einleitung berichtet. Aber Yagi teilte weiter mit, dass die durch Infusion mit Blutkörperchen aufgeschwemmter Lösung entstandene Polyzy thämie einige Tage dauerte und der Hämoglobingehalt fast mit der Erythrozytenzahl parallel ging, während keine nennenswerte Veränderung beim $\mathrm{Hämoglobinindex} \mathrm{eintrat,} \mathrm{und}$ dass dabei durch die Zunahme pseudoeosinophiler Leukozyten Leukozytose hervorgerufen wurde. Betreffs der Plasmakatalase stimmten meine Ergebnisse nach Infusion von Erythrozytenbrei mit denen Kurokawas überein, denn er fand bei Kaninchen keine nennens. werte Veränderung dieser Katalase, selbst wenn er intraperitoneal 10 oder sogar $20 \mathrm{ccm}$ Blut infundierte. Itami, ${ }^{36)}$ Roberts on ${ }^{37)}$ und $\mathrm{Oda}^{38}$ teilten mit, dass bei experimenteller Polyzythämie die Resistenz der Erythrozyten sank, was aber meine Ergebnisse nur zum Teil bestätigten. Daraus, dass durch Infusion roten Blutkörperchenbreis leicht experimentelle Polyzythämie hervorgerufen werden kann und dabei die Plasmakatalase nicht zunimmt, ist also zu ersehen, dass die transfundierten Erythrozyten im Körper des Empfängers unzerstört und ohneHämolysewirkung bleiben, also unbeschädigt resorbiert werden und sich eine Zeitlang brauchbar erhalten.

(b) Intraperitoneale Infusion ihres eigenes Erythrozytenbreis bei durch Aderlass blutarm gewordenen Kaninchen.

3 Kaninchen liess ich zunächst bis zu 15 oder $20 \mathrm{ccm}$ Blutverlust pro kg zur Ader und infundierte dann den aus dem entnommenen Blut hergestellten roten Blutkörperchenbrei am 2. Tag, der durch die Kontrollversuche schon als der Tag mit Maximalanämie festgestellt worden war. Wie Tabelle 6 zeigt, begann die Erythrozytenzahl, schon gleich nach der Infusion, stark zuzunehmen, und erreichte bei jedem Fall etwa nach 10 Tagen wieder ihren Normalwert. Der Hämoglobingehalt erforderte aber zur Wiederherstellung eine noch längere Zeit. Die Leukozytenzahl hatte zwar durch Aderlass zugenommen, 
nahm aber durch die Infusion vorübergehend wieder ab und dann abermals zu und kehrte am 3. Tage wieder zur Norm zurück. Die Blutkatalase hatte nach dem Aderlass allmählich abgenommen und wurde nach der Infusion zwar nicht sofort beeinflusst, nahm aber am nächsten Tage schnell zu und erreichte 4, 5 oder 6 Tage nach der Infusion schon wieder den Normalwert und nahm weiter zu, weshalb auch die Steigerung ihres Indexes mit der Besserung der durch Aderlass hervorgerufenen Anämie zeitlich übereinstimmte. Die Plasmakatalase nahm gar nicht zu. Die Erhöhung der Erythrozytenresistenz war fast so gross wie bei der Aderlassanämie der Kontrollversuche.

Oczesalski u. Sterling ${ }^{39}$ meinten, dass bei gesunden Kaninchen Aderlässe in Verbindung mit Infusion des eigenen Bluts nicht shaden, ja, im Gegenteil nicht nur die Resistenz roter Blutkörperchen steigern, sondern auch deren $\mathrm{Zahl}$ vermehren. $\mathrm{Ok}$ a berichtete, dass bei durch Aderlass blutarm gewordenen Kaninchen die Besserung der Anämie durch dauernde Verabreichung getrockneten Erythrozytenpulvers per os nicht nur stark gefördert wurde, sondern dass die Versuchstiere gleich nach der Erholung vorübergehend auch deutliche Polyzythämie zeigten. Kurokaw a teilte mit, dass die Plasmakatalase durch Aderlässe zusammen mit intraperitonealer Infusion des eigenen Bluts gar nicht beeinflusst werde.

Also wurde das transfundierte Blut auch bei diesen Versuchen ebenso wie bei den vorhergehenden ungeschädigt resorbiert und nützlich verwandt, sodass die Plasmakatalase nicht zunahm und die Anämie sehr gebessert wurde; das konnte ich durch diese Versuche bestätigen.

(c) Intraperitoneale Infusion teilweise hämolysierten Erythrozytenbreis bei gesunden Kaninchen.

Zur.Herstellung teilweise hämolysierten Erythrozytenbreis führte ich von der schon erwähnten, mit Blutkörperchen aufgesch wemmten Lösung die zu benutzende Menge in ein anderes Spitzglas über, um sie zu zentrifugieren, worauf ich die obere Schicht entfernte und dann so lange sterilisiertes und destilliertes Wasser hinzufügte, bis die anfängliche Blutmenge wieder erreicht wurde, um Hämolyse hervorzurufen, und dies weiter mit $0,9 \%$ Kochsalz mischte. Zur Infusion vermischte ich dies noch mit einer Lösung aus nicht aufgelösten Blutkörperchen. Auf diese Weise wurden nur 50 oder $40 \%$ des Bluts hämolysiert, das einem anderen Kaninchen zu $20 \%$ pro kg entnommen war. Und hiermit kam ich nun endlich zu meinen eigenen Versuchen. Wenn man eine grössere Menge hämolysierten Bluts damit 
mischte, dann starben die Versuchstiere ohne Ausnahme. Wie aus den Ergebnissen der Tabelle 7 zu ersehen, begaun die Erythrozytenzahl, 1-2 Stunden nach der Infusion (nur beim zeitlich untersuchten Fall 3, bei dem sie gleich danach vorübergehend zunahm, nach 3 Stunden), abzunehmen, und erreichte nach 4-7 Tagen ihr Minimum, kehrte aber bei jedem Fall ungefähr nach oder auch noch vor 3 Wochen wieder zur Norm zurück. Die Zu- oder Abnahme des Hämoglobinge. halts ging fast mit der der Erythrozytenzahl parallel. Die Blutkatalase wurde zwar gleich nach der Infusion fast gar nicht beeinflusst, nahm dann aber mit der Erythrozytenzahl ab und erreichte fast zugleich mit dieser auch ihren Minimalwert, dann aber nahm sie stark zu und kehrte 7-10 Tage früher als die Erythrozytenzahl wieder zu ihrem Normalwert zurück, und dementsprechend stieg auch der Katalaseindex nach und nach. Die Benzidinreaktion des Plasmas wurde schon gleich nach der. Infusion positiv; die Katalase nahm dabei stark zu, erreichte schon am 2. Tage ihren Naximalwert, nahm dann aber schnell ab und kehrte frühestens am 4. Tage oder spätestens binnen einer Woche wieder zu ihrem Normalwert zurück. Die Erythrozytenresistenz stieg im Maximum um 0,06-0,1\%. Die Leukozytenzahl und der Wechsel der Leukozytenbilder waren den Ergebnissen des Abschnitts a ähnlich, nur die unreifen Formen traten etwas deutlicher als bei diesem auf.

Obige Ergebnisse möchte ich nun mit denen in der Literatur vergleichen. $\mathrm{Ono}^{40)}$ teilte in seiner Arbeit über die Funktion bei Erythrozytenneubildung mit, dass durch parenterale Infusion einer geeigneten Menge von Erythrozytenlösung bei Kaninchen ihre hämatopoetische Funktion gefördert werde und die Versuchstiere da. durch vorübergehend Polyzythämie zeigten, dass diese Funktion aber durch Infusion einer grossen Menge gestört werde, sodass Abnahme der Erythrozytenzahl die Versuchstiere anämisch machen könne. Meine Versuche sind diesem Versuch mit Infusion einer grossen Menge fast gleich. Takiza wa meinte auch, dass durch intraperitoneale Infusion von $20 \mathrm{ccm}$ hämolysierten Bluts bei gesunden Kaninchen die Erythrozytenzahl und der Hämoglobingehalt etwas abnähmen, und dass die Benzidinreaktion des Plasmas schon gleich nach der Infusion positiv und auch der Wert der Katalase sichtlich grösser würde; folglich wirke intraperitoneale Infusion hämolysierten Bluts auf die roten Blutkörperchen des Versuchstiers auflösend. Barratt $u$. York ${ }^{* 1)}$ berichteten, dass durch Injektion ausserhalb des Körpers aufgelöster Erythrozyten oder einer Hömoglobinlösung beim 
Tier zwar Hämoglobinurie eintrete, aber für das in den Harn übergegangene Hämoglobin liess sich die Frage noch nicht beantworten, ob schon dadurch irgendwelche Veränderungen im Körper des Versuchstiers selbst erfolgten oder nicht. Dass Infusion einer übermässigen Lösungsmenge hämolysierten Bluts oder einer Hämoglobinlösung Hämoglobinharn erzeugt, gilt zwar allgemein als Tatsache, aber man weiss bis heute noch nichts Sicheres darüber, wie das Verhältnis zwischen der Hämoglobinlösung und den Erythrozyten des Empfängers ist. Aber meine Versuche ergaben schon nicht nur Abnahme der Erythrozytenzahl und des Hämoglobingehalts sowie Zunahme del Plasmakatalase, sondern auch das Entstehen von Hämoglobinharn, weshalb man mit Recht schliessen darf, dass hämolysiertes Blut auf rote Blutkörperchen auflösend wirke. Weiter hat schon Ishizawa aus unserem Institut experimentell festgestellt, dass Infusion artgleichen Hämoglobins in die Blutbahn die roten Blutkörperchen des Versuchstiers auflöst, worüber aber noch nichts veröffentlicht worden ist.

(d) Intraperitoneale Infusion teilweise hämolysierten Erythrozytenbreis bei durch Aderlass anämisch gewordenen Kaninchen.

Bei durch Aderlass anämisch gewordenen Kaninchen führte ich dieselben Versuche wie im vorhergehenden Abschnitt (c) aus. $3 \mathrm{Ka-}$ ninchen entnahm ich zuerst $20 \mathrm{ccm}$ Blut pro $\mathrm{kg}$ und spritzte ihnen, wenn die Anämie danu am stärksten geworden, vom entnommenen Blut hergestellten teilweise hämolysicrten Erythrozytenbrei ein, wodurch beim 1 . Fall $25 \%$ Blut und beim 2. und 3 . je 50\% hämolysiert wurden. Die Ergebnisse sind in Tabelle 8 wiedergegeben. Die Erythrozytenzahl nahm beim 1. und 2. Fall gleich nach der Infusion und beim 3. erst nach vorübergehender Zunahme ab, neigt aber schon am nächsten Tag zur Zunahme und stellte sich beim 1. nach 14 Tagen, beim 2. und 3. nach 17 Tagen wieder vollkommen her. Der Hämoglobingehalt wurde aber noch später normal, und der Hämoglobinindex blieb immer unter 1. Die Leukozytenzahl war gleich nach der Infusion in $\mathrm{Zu}$ - oder Abnahme unbestimmbar und nahm am nächsten Tag bei jedem Fall zu, doch dauerte es nicht lange, bis sie wieder zu ihrer Norm zurückkehrte. Die Ergebnisse betr. der Blutkatalase und deren Index waren ebenso gute wie bei denen des Abschnitts b, ausgenommen dass die Wiederherstellung des Katalasewerts ein bisschen früher als bei diesen war. Die Plasmakatalase wurde zwar durch 
Blutentnahme gar nicht beeinflusst, nahm aber durch Infusion des Erythrozytenbreis sehr stark zu und erreichte am 2. Tag ihren Maximalwert, dann aber nahm sie schnell ab und kehrte nach 4-5 Tagen wieder zu ihrem Normalwert zurück. Die maximale Erhöhung der Erythrozytenresistenz betrug durch Infusion zu $25 \%$ hämolysierten Bluts $0,08 \%$ und durch die zu $50 \%$ hämolysierten Bluts $0,1-0,14 \%$. Die Blutbilder stimmten mit den Ergebnissen des Abschnitts b fast überein.

Ita $\mathrm{i}^{+2}$ fand, dass bei durch Aderlass blutarm gewordenen Kaninchen intraperitoneale Infusion einer Erythrozytenlösung die Besserung der Anämie fördert, und meinte, dies käme wohl daher, dass die zerstörten Erythrozyten selbst entweder unmittelbar als blutbildende Stoffe dienten oder hämatopoetische Organe so sehr reizten, dass ihre Funktion dadurch gefördert würde. Nun aber war bei meinen Ergebnissen der Verlauf der Besserung der Anämie sogar dem der durch Aderlass hervorgerufenen beim Kontrollversuch ganz ähnlich. Von Itam is Angabe aus meinen Ergebnissen betrachtend, lässt sich vielleicht Folgendes annehmen: erst, als die durch Aderlass am höchstens gestiegene Anämie zur Besserung neigte, wirkte das infundierte hämolysierte Blut auf die Erythrozyten des Empfängers so auflösend, dass die Erythrozytenzahl vorübergehend abnahm, und weiter, erst als die hämatopoetische Funktion infolge Blutentnahme im Begriff war, zu wirken, störte zwar eine grosse Menge hämolysierten Bluts, entgegengesetzt wirkend, vorübergehend diese Funktion, ja hemmte sie sogar; dann aber dienten solche Blutbestandteile selbst vielmehr zur Förderung der Funktion, sodass sich dabei die Anämie schon einige Tage früher als selbst bei den Versuchen des vorhergehenden Abschnitts c besserte. Itami und Pratt meinten, dass bei durch Aderlass anämisch gewordenen Kaninchen intraperitoneale Infusion hämolysierten Bluts die Resistenz der Erythrozyten stark erhöhe, und nach Wiederholung solcher Versuche erklärte Takiz a wa, dass sie sich dabei sehr stark erhöhte und zugleich die Plasmakatalase auch stark zunalum.

Aus obigen Ergebnissen erhellt, dass bei Kaninchen Infusion teilweise hämolysierten Erythrozytenbreis zwar vorübergehend die Erythrozytenzahl senkte, die sich aber dann allmählich wieder herstellte, und dass der Verlauf der Besserung der Anämie hierbei mit dem bei einfacher, durch Aderlass hervorgerufener Anämie des Kontrollversuchs übereinstimmte. Und weiter stimmten dabei die starke $\mathrm{Zu}$ nahme der Plasmakatalase und das Auftreten von Hämoglobinurie mit 
den Ergebnissen des Abschnitts c überein, bei dessen Versuchen gesunden Kaninchen teilweise hämolysierter Erythrozytenbrei eingespritzt wurde.

(e) Intraperitoneale Infusion mit Galle gemischten Erythrozytenbreis bei gesunden Kaninchen.

Nun verglich ich die Ergebnisse nach intraperitonealer Infusion durch Kaninchengalle aufgelösten Bluts mit den Ergebnissen des Abschnitts $\mathrm{c}$ und d. Die Galle wurde dem Kaninchen durch Laparotomie unmittelbar aus der Gallenblase entnommen. 3 gesunden Kaninchen wurden $10,15,35$ und 2 anderen je $40 \mathrm{ccm}$ mit je $0,4-0,5 \mathrm{ccm}$ Galle gemischten und dadurch hämolysierten Erythrozytenbreis eingespritzt. Wie aus Tabelle $9 \mathrm{zu}$ ersehen, nahm die Erythrozytenzahl in allen Fällen gleich nach der Infusion zu, aber nach dem 2. Tage allmählich ab, wodurch die Kaninchen anämisch wurden, und nach 4-5 Tagen erreichte sie ihr Minimum, aber erst nach 18-22 Tagen kehrte sie wieder zur Norm zurück. Weil also alle Fälle, wenn auch mehr oder weniger nacheinander, doch beinahe zugleich wieder zur Norm gelangten, erkennt man daraus, dass dies nicht sowohl von der benutzten Menge des Elythrozytenbreis als hauptsächlich von der der Galle abhing. Auch lässt sich wiederum verstehen, dass, weil die Stärke der Abnahme der Erythrozytenzahl gar nicht mit der Menge des Erythrozytenbreis zusammenhing, diese Abnahme durch die Bestandteile und die Konzentration der Galle sowie die verschieden grosse Empfindlichkeit jedes einzelnen Versuchstiers bei allen Fällen vielmehr voneinander abwich. Der Hämoglobingehalt nahm immer in Übereinstimmung mit der Erythrozytenzahl zu oder $a b$, und der Hämoglobinindex blieb stets grösser als 1. Die Leukozytenzahl nahm gleich nach der Infusion bei 3 Fällen zu und blieb bei 2 unverändert, war aber am 2. Tage in allen Fällen vergrössert. Dann kehrte sie beim 1., 2 . und 4. Fall schon nach 4- 7 Tagen wieder zur Norm zurück, nahm dagegen beim 3. und 5. Fall, bei denen sie nach 3-5 Tagen nu: vorübergehend abgenommen hatte, wieder weiter zu. Die Blutkatalase nahm gleich nach der Infusion zu und zusammen mit der Abnahme der Erythrozytenzahl ab, kehrte aber bei weitem früher als diese wieder zum Normalwert zurück. Der Katalaseindex sank trotz der Infusion und der Anämie nicht, sondern stieg, nur bei dem 8. Tage nach der Infusion gestorbenen Fall blieb er fast immer unverändert. Die Zunahme der Plasmakatalase war zwar der des Abschnitts $\mathrm{c}$ und d ähnlich, erschien jedoch etwas stärker. Als ich bei einem Fall den 
Zustand des Harns und der Körperwärme noch besonders beobachtete, fiel am 1. und 2. Tage Hämoglobinurie auf, und die Körperwärme war nach der Infusion nur wenig gestiegen. Die Erythrozytenresistenz im Maximum erhöhte sich um 0,04-0,12\%, und die im Minimum sank gleich nach der Infusion nur etwas. Die Leukozytenbilder veränderten sich ebenso unerheblich wie beim Abschnitt c. Kurokawa teilte mit, dass bei Kaninchen die Plasmakatalase gleich nach intravenöser Infusion von $0,2 \mathrm{ccm}$ Galle am stärksten zunahm und mit der Zeit allmählich sank. Daraus aber, dass sie bei meinen Versuchen erst am Tage nach der Infusion am stärksten zunahm, erhellt, dass sich der Resorptionszustand bei meinen Versuchen von dem bei den seinen durchaus unterschied. Takizaw a fand, dass die Plasmakatalase infolge der Ligatur des Ductus choledochus zunahm, und führte dies darauf zurück, dass der auf der Unterbindung beruhende Übergang der Gallenbestandteile in die Blutbahn Hämolyse bewirkt hatte.

Also rief Infusion von Erythrozytenbrei zusammen mit Galle in den Empfängern Hämolyse hervor, und zu ihrer Besserung waren etwa 3 Wochen nötig; das ist den Ergebnissen des Abschnitts c sehr ähnlich, wo den Kaninchen teilweise hämolysierter Erythrozytenbrei infundiert wurde. Aber die Zunahme der Plasmakatalase war hier noch grösser als beim Abschnitt c, was darauf beruht, dass die Gallenbestandteile noch stärker hämolytisch wirkten. Es scheint, dass diese Zunahme nicht sowohl mit der gemischten Gallenmenge als vielmehr mit der hämolysierten Blutmenge übereinstimmte.

(f) Intraperitoneale Infusion mit Leberbrei gemischten Erythrozytenbreis bei gesunden Kaninchen.

Falls ein intraperitoneales Organ, namentlich Leber oder Milz, durch Verletzung gequetscht und innere Blutung hervorgerufen ist, so muss man wissen, wie sich die Stücke dieser gequetschten Organe, besonders die der Leber, zu den Blutkörperchen verhalten. Dass bei der Quetschung der Leber die Galle in die Bauchhöhle tritt, ist denkbar, und dass die Galle auf Blutkörperchen lä̈molysierend wirkt, stellte ich schon bei meinen vorigen Versuchen fest. Da liabe ich nun als Vorversuche vor den Versuchen mit Leber- und Milzquetschung den Einfluss intraperitonealer Infusion mit Leber- oder Milzbrei gemischten Erythrozytenbreis auf den lebenden Körper untersucht. Ein einem anderen Kaninchen operativ und aseptisch entnommenes Leberstück wurde in einem mit Kochsalzlösung befeuchteten, kleinen Mörser so fein als möglich zermahlen und nach Entfernung der Gefässe 
und Bindegewebsstücke eine bestimmte Menge davon in eine mit Blutkörperchen aufgeschwemmte Kochsalzlösung getan. Dann spritzte ich dieses Gemisch mit einem kleinen Spritzrohr in die Schnittwunde der Bauchdecke, weil mir Infusion durch eine Spritze, selbst bei so fein zermahlenem Gewebe, fast unmöglich erschien. Von 2 Kaninchen spritzte ich dem einen 20 und dem anderen $30 \mathrm{ccm}$ der mit Blutkörperchen aufgeschwemmten Kochsalzlösung zusammen mit $7-10 \mathrm{~g}$ Leberbrei ein. Wie in Tabelle 10 wiedergegeben, nahm die Erythrozytenzahl nicht dem Gewicht des Leberbreis, sondern der Menge des Erythrozytenbreis entsprechend zu, und zwar dauerte diese Zunahme 2 oder 3 Tage, aber dann schwankte dieEry throzy tenzahl um ihren Normalwert. Die Plasmakatalase nahm gleich nach der Infusion nur ein wenig zu und erreichte am 2. Tag ihren Maximalwert, behielt dann aber noch einige Tage einen erhöhten Wert. Die Erythrozytenresistenz wurde nicht nennenswert beeinflusst, ausgenommen dass gleich nach der Infusion ihr Minimum ein wenig schwächer wurde. Die Leukozytenbilder unterschieden sich nicht wesentlich von denen des Abschnitt a.

Nach obigen Ergebnissen erfuhr die Erythrozytenzahl zwar vorübergehend Polyzythämie, stellte sich aber schon nach einigen Tagen wieder her und behielt weiter ihre Norm. Die Plasmakatalase nahm nur sehr wenig zu, was sich ausschliesslich auf die Wirkung des gemischten Leberbreis zurückführen lässt.

\section{(g) Intraperitoneale Infusion mit Milzbrei gemischten Erythrozytenbreis bei gesunden Kaninchen.}

Eine einem anderen Kaninchen operativ entnommene Milz wurde in der im vorhergehenden Abschnitt erwähnten Weise in Brei verwandelt und dieser dann in eine mit Blutkörperchen aufgeschwemmte Kochsalzlösung getan. Wie aus den Ergebnissen der Tabelle $11 \mathrm{zu}$ ersehen, zeigte sich die Erlhöhung der Erythrozytenzahl durch die Infusion zwar vorübergehend in der Polyzythämie, kehrte dann aber allmählich wieder zur Norm zurück; dabei wurde keine Anämie hervorgerufen. Der Hämoglobingehalt und die Blutkatalase verhielten sich ganz gleich wic nach der Infusion von Leberbrei, aber die Plasmakatalase nahm hier nicht zu. Das Minimum der Erythrozytenresistenz sank auch etwas. Die Leukozytenbilder waren denen in vorhergehenden Abschnitt ähnlich. Aber das Auftreten junger Formen von basophilen gekörnten Erythrozyten und kernhaltigen roten Blutkörperchen ist anders als bei intraperitonealer Infusion von Erythrozytenbrei bei gesunden Kaninchen. 
Dass bei diesem Versuch die Plasmakatalase gar nicht bedeutend zunahm, war ähnlich wie bei der Infusion einfachen Erythrozytenbreis. Die Milz des Kaninchens wiegt gewöhnlich sehr wenig' und wog auch bei meinen 2 Fällen nur 0,8 und $1,3 \mathrm{~g}$. Deshalb war es natürlich, dass eine so kleine Menge Brei der eigentlich an Organkatalase verhältnismässig armen Milz auch durch Hinzufügung keine starke Zunahme der Plasmakatalase hervorrief.

Bei der Zusammenfassung der Ergebnisse aller obigen Abschnitte a-g lässt sich Folgendes sagen : Durch intraperitoneale Einspritzung von lauter Blutkörperchenbrei trat keine besondere Störung auf, sondernn die infundierten Erythrozyten wirkten günstig, was beim Anämieversuch besonder's auffiel; dabei trat nichts ein, was entweder auf Resorption hämolysierten Bluts in die Blutbahn oder auf Hämolyse in dieser hindeutete. Dagegen starben die Versuchstiere durch Infusion von $20 \mathrm{ccm}$ mit Blutkörperchen aufgeschwemmter Kochsalzlösung (pro kg Körpergewicht), in die über 40-50\% iger hämolytischer Erythrozytenbrei getan worden war; und dabei ermittelte ich, dass das hämolytische Blut von der Blutbahn resorbiert wurde und in ihr Hämolyse eintrat und dass dadurch die Erythrozyten abnahmen. Dies fand ich nicht nur nach der Infusion eines Gemischs mit hämolysiertem Blut, sondern auch mit Galle oder Leberbrei, was jedoch nach der eines Gemischs mit Milzbrei unmöglich war. Also wirken Galle und Leberbrei beide auf rote Blutkörperchen hämolysierend, weshalb die Ergebnisse durch Infusion eines Gemischs mit jener oder mit diesem natürlich mit denen durch Infusion eines Gemischs mit hämolytischem Blut übereinstimmen müssen. Zugleich liesse es sich auch denken, dass dabei das hämolysierte Blut von der Blutbahn resorbiert wird und dann Hämolyse in der Blutbahn eintritt. Verhält es sich damit wirklich so, damn kann natürlich auch gefolgert werden, dass bei intraperitonealer Verblutung, wo zugleich ausgeflossene Galle eine ziemlich grosse Menge Blut hämolysiert, dieses hämolytische Blut in einer so grossen Menge von der Blutbahn resorbiert wird, dass endlich der Tod eintritt. Es dient noch zur Bestätigung dieser Folgerung, dass bei meinen Versuchen die Infusion eines Gemischs mit Milzbrei, im Gegensatz zu der eines Gemischs mit Leberbrei, nichts zeigt, was auf Resorption hämolysierten Bluts in die Blutbahn oder Hämolyse hinweisen Kö̈nnte.

Dann habe ich endlich nach all diesen Vorversuchen die folgenden Versuche ausgeführt, um die Ursache des auf innerer Verblutung bei Leber- oder Milzquetschung beruhenden Todes zu ermitteln. 


\section{Hauptversuche.}

(a) Innere Verblutung bei Leberquetschung.

Durch Verletzung intraperitonealer Organe rief ich hier innere Verblutung hervor und untersuchte dann den Resorptionszustand des in die Bauchloöhle ausgeflossenen Bluts und dessen Einfluss auf den lebenden Körper. Nach der schon beim Kontrollversuch erwähnten Methode öffnete ich die Bauchhöhle, steckte daun die Finger durch den Schnitt und liess das Lebergervebe durch Quetschung bluten, worauf ich die Bauchdecke wieder zunähte.

Wie aus Tabelle 12 zu ersehen, verliefen die Veränderungen je nach der Stärke der durch Quetschung hervorgerufenen Verletzung auch verschieden. Aber gleich nach der Operation nahm die Erythrozytenzahl in allen Fällen vorubergehend zu und dann allmählich ab. Diese Abnahme war beim 1. und 2. Fall nur selrr gering, sodass die Erythrozytenzahl nach 7-10 Tagen schon wieder zur Norm zurückkehrte, aber beim 3 . und 4 , die verhältnismässig ausgedehnte Verletzungen erlitten hatten, ziemlich stark, sodass die Erythrozytenzahl zu ihrer Wiederherstellung sogar 18-19 Tage benötigte. Der Hämoglobingehalt ging der Hauptsache nach mit der Erythrozytenzahl parallel, und der Hämoglobinindex erhöhte sich gleich nach der Operation etwas, sank aber in einigen Tage und blieb, mit Ausnahme des 3. Falls, meistens unter 1. Die Leukozytenzahl nahm gleich nach der Operation zu, dann aber war ihre Veränderung ganz unbestimmbar, denn die Leukozytenzahl kehrte bald schnell wieder zur Norm zurück, bald aber blieb sie noch lange Zeit so, d. h. erhöht. Die Blutkatalase nahm in den meisten Fällen gleich nach der Operation ab und mit der Abnahme der Erythrozytenzahl immer stärker, neigte dann mit der Besserung der Anämie zwar etwas zur Zunahme, aber nicht so deutlich wie bei den Vorversuchen, weshalb sich auch der Blutkatalaseindex nur ganz wenig erhöhte. Die Plasmakatalase begann gleich nach der Operation zuzunehmen, erreichte am 2. Tag ihren Maximalwert und nahm dann allmählich ab. Die Grösse dieser $\mathrm{Zu}$ nahme stimmte fast genau mit der der Quetschung überein, d. h. sie war umso stärker, je grösser die Ausdehnung der Quetschung war; beim 1. Fall, der eine daumenballengrosse Quetschung erlitt, trat die Zunahme nicht gleich nach der Operation, sondern erst am 2. Tage nur sehr leicht auf, während hingegen beim 3 . und 4. die Plasmakatalase schon gleich nach der Operation stark zunahn und erst nach 5-6 Tagen wieder ihren Normalwert erreichte. Insbesondere beim 4. Fall 
nahm sie um mehr als das Dreifache zu, obwohl die Hämoglobinreaktion dabei negativ blieb. Die Erhöhung der Erythrozytenresistenz war auch je nach der Ausdehnung der Quetschung bei jedem Fall verschieden, nur dass die Resistenz beim 1. fast unverändert blieb. Die Veränderungen der Leukozy tenbilder und das Auftreten junger Formen waren noch etwas auffallender als beim Abschnitt der Kontrollversuche.

Bekanntlich ist die Leber reich an Organkatalase; z. B. enthält die Leber des Kaninchens nach der Mitteilung Och is 72,5\% Katalase im Vergleich mit der des Bluts, und Rosenbaum ${ }^{43)}$ und Tuschtschen $\mathrm{o}^{\text {(t) }}$ berichteten auch, dass die Leber unter allen Organen an Katalase am reichsten sei. Deshalb ist es nur natürlich, dass die Plasmakatalase infolge der Quetschung des an Katalase reichen Organs zunimmt. Kurokawa fand bei mechanischer Verletzung der Leber des Kaninchens starke Zunahme der Plasmakatalase und führte die Ursache dieser Zunahme auf den Zerfall der Leberzellen zurück, leugnete aber, auf Grund seiner Kontrollversuche, die Wirkung der Auflösung durch parenchymatöse Blutung ausgetröpfelten Bluts oder der Laparotomie. Aber Kurokawa tupfte bei seinen Versuchen das ausgeflossene Blut im Operationsgebiet sorgfältig auf, wohingegen ich absichtlich bluten, ja sogar das so ausgeflossene Blut immer noch in der Bauchhöhle bleiben liess. Also besteht ein wesentlicher Unterschied zwischen meinen Versuchen und den seinen, sodass ich die Zunahme der Plasmakatalase nicht so ausschliesslich der Wirkung des Übertritts der Organkatalase ins Blut zuschreiben kann wie Kurokawa. Denn man darf nicht unbeachtet lassen, dass dabei die Auflösung des ausgeflossenen Bluts, d. h. mechanischer Zerfall der Blutkörperchen während des Operationseingriffs, oder Elythrozytenauflösung durch Bestandteile der Galle, die zugleich mit der Blutung im Operationsgebiet und vielleicht dann dauernd aus der Quetschwunde ausfliesst, auch mitwirken müssen, worüber ich nach den Versuchen des folgenden Abschnitts noch weiter sprechen werde. Was die Blutkatalase betrifft, so teilte $\mathrm{Jin}^{4 i 3}$ mit, dass zur Zeit der Leberschädigung die Ergebnisse je nach der Methode und der Grösse der Schädigung zwar verschieden seien, aber dass sie der Hauptsache nach anfangs vorübergehend zunehme. Aber bei meinen Versuchen nahm sie im Gegenteil der Hauptsache nach ab.

Also machte ich bei meine Versuch die Versuchstiere anämisch und liefs Abnahme der Blutkatalase und starke Zunahme der. Plasmakatalase erfolgte. Und die Stärke dieser Anämie und Zunahme scheint fast mit der Grösse des Quetschungsgebiets parallel zu gehen. 


\section{(b) Innere Verblutung bei Milzquetschung.}

Hier führte ich bei der Milz, die verhältnismässig arm an Organkatalase ist und als ganz frei von Gallenbestandteilen zu betrachten ist, den gleichen Versuch wie bei der Leber aus und verletzte die Milz durch Quetschung so vollkommen wie möglich. Wie in Tabelle 13 wiedergegeben, nahm die Erythrozytenzahl gleich nach der Operation vorübergehend $z u$, dann aber allmählich $a b$ und erreichte nach 4-5 Tagen ihr Minimum, veränderte sich dann zwar mehr oder weniger, blieb aber lange Zeit danach fast unverändert. Der Hämoglobingehalt nahm, mit der Erythrozytenzahl übereinstimmend, zu oder ab, aber der Hämoglobinindex zeigte keine bestimmbare Beziehung zur Veränderung der Erythrozytenzahl. Die Leukozytenzahl nahm besonders stark zu und erreichte schon am Tage nach der Operation ihr Maximum, nahm etwa nach 3-4 Tagen vorübergehend ab, dann aber wieder zu und blieb dabei. Die Blutkatalase war gleich nach der Operation entweder unverändert oder nur ein wenig vermehrt, nahm dann aber mit der Erythrozytenzahl ab, weshalb ihr Index zwar gleich nach der Operation vorübergehend stieg, dann aber allmählich sank, also keine starke Erhöhung zeigte. Besonders bei dem mit dem Tode endenden Fall sank er bloss immer. Die Plasmakatalase nahm nur sehr wenig zu. Das Maximum der Erythrozytenresistenz stieg besonders hoch und machte $0,16-0,26 \%$ aus. Die Veränderung der Leukozytenbilder war etwas stärker als bei der Probelaparotomie, und die Zunahme pseudoeosinophiler Leukozyten dauerte hier noch länger an als bei dieser. Unter den jungen Formen der Erythrozyten fielen besonders die kernhaltigen Erythrozyten auf.

Nach der Angabe Ochis beträgt der Katalasegehalt der Milz $36,5 \%$ gegen den des Bluts, also $\frac{1}{2}$ so viel wie bei der Leber. Deshalb ist auf Grund der schon erwähnten Ergebnisse der Leberquetschung, von Kurokawa sowohl wie von mir, und auch nach den Ergebnissen der Nierenquetschung von Takizawa mit Recht zu erwarten, dass die Plasmakatalase auch durch Milzquetschung zunimmt. Aber nach meinem Versuch nahm sie zwar bei einem Fall ganz wenig zu, zeigte sich aber bei anderen Fällen im Vergleich mit den Ergebnissen des Kontrollversuchs gar nicht vermehrt. Was das Verhältnis zwischen Milz und Blutkatalase betrifft, so meinte $\mathrm{Ri}^{4{ }^{40}}$ dass die Katalase nach Milzexstirpation ab-, durch Injektion von Milzextraktlösung hingegen zunehme, aber bei meinen Milzquetschungsversuchen nahm sie gleich nach der Operation vorübergehend zu und am nächsten Tag 
und dann immer weiter $a b$. Betr. der Leukozytose berichteten Takagi u. Aibara, ${ }^{47}$ Vulpius ${ }^{48}$ und Schulze, zahl nach der Operation stark zunahm und ihre Wiederherstellung bei weitem später erfolgte als bei der Probelaparotomie; das stimmt ganz mit den Ergebnissen meiner Milzquetschungsversuche überein. Betreffs des Verlaufs der Erythrozytenresistenz nach Milzexstirpation behaupteten die einen ihre Erhöhung und die anderen ihre Senkung, aber es scheint mir, dass die für Erhöhung eintretenden Forscher im ganzen die anderen an Zahl übertreffen. Obgleich meine Versuche denen der Milzexstirpation nicht gleich sind, so kann man sie doch auf Grund der infolge der Quetschung anormal gewordenen Milzfunktion ihnen fast gleichstellen. Selbst bei den Fällen meiner Versuche, deren Erythrozytenzahl nur ganz wenig sank, nahm die Resistenz ziemlich stark zu; schon aus diesem Beispiele ist zu ersehen, dass unvollständige Milzfunktion die Erythrozytenresistenz des Tiers jedenfalls erhöht.

Was die jungen Formen der Frythrozyten betrifft, so bezeichneten Hirschfeld u. Weiner ${ }^{\text {ton }}$ das Auftreten der Jolly-Körperchen nach der Operation als Eigentümlichkeit, was auch von Sakai u. a. bestätigt wurde. Aber Nagano $0^{51}$ berichtete, dass bei Kaninchen nach Milzexstirpation weder Jolly-Körperchen noch abnorme Erythroblasten auftraten, und Bittn e $r^{\text {529 }}$ machte auch eine ähnliche Mitteilung. Bei meinen Versuchen war die Zunahme der Erythroblasten etwas stark, Jolly-Körperchen wurden aber nicht beobachtet.

Wie aus obigen Ergebnissen zu ersehen, wurden die Versuchstiere durch meine Versuche in eine so starke Anämie versetzt, dass ihre Besserung nur sehr langsam erfolgte und noch ziemlich viele Tage zu erfordern schien. Die Plasmakatalase war entweder unverändert oder nahm nur ein wenig zu, woraus sich ersehen lässt, dass das durch Milzquetschung in die Bauch höhle ausgeflossene Blut grösstenteils nicht zerstört, sondern resorbiert wird. Infolgedessen ist es auch möglich, dass die im vorhergehenden Abschnitt durch Leberquetschung hervorgerufene Zunahme der Plasmakatalase nicht auf mechanischem Zerfall des ausgeflossenen Bluts, sondern hauptsächlich auf dur'ch Bestandteile der Lebergalle bewirkter Hämolyse beruht.

\section{Zusammenfassung.}

Alle obigen experimentellen Ergebnisse seien hier noch einmal kurz zusammengefasst. Was die intraperitoneale Infusion des 
Erythrozytenbreis betrifft, so fand ich, dass sie bei gesunden Kaninchen ohne weiteres vorübergehend Polyzythämie hervorrief und sogar bei durch Aderlass anämisch gewordenen Kaninchen die Besserung der Anämie so stark förderte, dass diese dabei in Vergleich mit der natürlichen Besserung der auf Aderlass beruhenden Anämie bei den Kontrollversuchen sehr beschleunigt war. Dabei wurde die Plasmakatalase durch die Infusion gar nicht beeinflusst, was beweist, dass das infundierte Blut im Körper des Empfängers nicht zerstört, sondern gut resorbiert und benutzt wird; das stimmt mit den Ergebnissen vieler Vorgänger überein. Weiter machte intraperitoneale Infusion zum Teil mit destilliertem Wasser oder mit Galle aufgelösten Erythrozytenbreis jedes einzelne gesunde Kaninchen so stark anämisch, dass sie sich nur ganz langsam davon erholten, was lange Zeit erforderte. Dagegen war bei durch Aderlass anämisch gewordenen Kaninchen nach Infusion mit destilliertem Wasser zum Teil aufgelösten, d. h. teilweise hämolysierten Erythrozytenbreis die Besserung dieser Anämie derjenigen ähnlich, die ich bei meinen Kontrollversuchen als natürliche Besserung der durch Aderlass hervorgerufenen Anämie beobachtete. Und hierbei scheint Infusion teilweise hämolysierten Erythrozytenbreis die durch Aderlass schon etwas geförderte hämatopoetische Funktion weder besonders zu hemmen, noch besonders zu fördern, gleichsam als ob das hämolysierte Blut und der Erythrozytenbrei in ihren Wirkungen einander entgegenarbeiteten. Bei allen Fällen, denen Erythrozytenbrei zusammen mit durch destilliertes Wasser oder durch Galle hämolysiertem Blut infundiert wurde, nahm die Plasmakatalase stark zu, die Erythrozytenzahl aber zu gleicher Zeit ab, was vielleicht daher rührt, dass das resorbierte hämolysierte Blut zum Teil in den Kreislauf übergeht und dann als sekundäre Wirkung die Blutkörperchen der Versuchstiere auföst. Ferner nahm dabei der Hämoglobingehalt ab, oder nach der Infusion wurde auch Hämoglobinurie beobachtet, was die Angabe Takizawas bestätigt, dass hämolysiertes Blut die Blutkörperchen des Empfänger's auflöse. Infusion mit Organbrei gemischten Erythrozytenbreis rief vorübergehend Polyzythämie hervor, ebenso wie Infusion von lauter Erythrozytenbrei. Durch Infusion mit Leberbrei gemischten Erythrozytenbreis nahm die Plasmakatalase ein wenig, aber durch die mit Milabrei gar nicht zu, was wahrscheinlich auf dem Übergehen der Organkatalase und einer geringen Menge hämolysierten Bluts in die Blutbahn beruht.

Obgleich die Zu- oder Abnahme der Blutkatalase nicht immer. mit der Erythrozytenzahl parallel ging, nahm sie doch in den meisten 
Fällen zugleich mit dieser ab und erreichte etwa vor oder nach der Zeit, wo die Erythrozytenzahl am tiefsten sank, auch ihren Minimalwert, nahm dann aber so stark zu, dass sie in den meisten Fällen noch früher als die Erythrozytenzahl wieder zum Normalwert zurückkehrte und dann allmählich weiter zunahm. Und dies habe ich bei meinen Versuchen immer wieder beobachtet. Dementsprechend sank der Katalaseindex ganz selten, selbst wenn die Anämie maximal wurde, und stieg mit der Besserung der Anämie allmählich. Diese Erhöhung war namentlich beim Fall, der besonder's starke Anämie erlitten hatte, bedeutend, während bei dem Fall, der im Verlauf des Versuchs starb, der Katalaseindex gar nicht anstieg; aus diesem Ergebnis erhellt, dass die Bestimmung des Katalaseindexes zur Beurteilung der Prognose bei verschiedenartigen Anämien beitragen kann.

Die minimale osmotische Resistenz roter Blutkörper'chen gegen hypotonische Kochsalzlösung sank bei gesunden Kaninchen entweder durch Infusion von Erythrozytenbrei allein oder von ihm zusammen mit Organbrei nur etwas, wohingegen die maximale, insbesondere beim mikroskopischen Befund, sowohl durch Infusion teilweise hämolysierten Erythrozytenbreis bei gesunden Kaninchen sowie bei den durch Aderlass anämisch gewordenen als auch durch Quetschung eines intraperitonealen Organs immer stark anstieg, besonders nach Milzquetschung.

Betreffs des Leukozytenbilds nahmen nach jeder Infusion oder jedem Operationseingriff die pseudoeosinophilen Leukozyten stark zu und umgekehrt die relative Lymphozytenzahl zugleich ab; dies war bei den Versuchen aller Abschnitte allgemein der Fall. Aber inbezug auf den späteren Verlauf dieser beiden und andere Typen war zwischen den einzelnen Abschnitten und Fällen kein bemerkenswerter Zusammenhang und Unterschied festzustellen. Die jungen Formen der Erythrozyten wurden durch Infusion mit hämolysiertem Blut gemischten Erythrozytenbreis ebenso wie durch Quetschung eines intraperitonealen Organs ein wenig sichtbar, aber nach Milzquetschung waren nicht einmal die Jolly-Körperchen zu bemerken.

Die durch Quetschung eines intraperitonealen Organs hervorgerufene innere Blutung machte alle meine Versuchstiere anämisch, und die Schwere der Anämie wie der Verlauf ihrer Besserung gingen nach Leberquetschung fast mit der Ausdehnung des Quetschungsgebiets parallel, waren aber nach Milzquetschung je nach den einzelnen Individuen ganz verschieden, sodass sich danach keine bestimmte Beziehung feststellen liess, wozu noch kam, dass die Besserung ziemlich 
lange Zeit zu erfordern schien. Die Plasmakatalase nahm zwar durch Leberquetschung stark, aber durch Milzquetschung fast gar nicht zu ; das beruhte einerseits auf der Verschiedenheit zwischen dem Organkatalasegehalt der Leber und dem der Milz, andererseits aber auf der hämolytischen Wirkung der infolge der Quetschung dauernd aus der Quetschwunde ausfliessenden Galle auf das schon ausgeflossene Blut, denn die Plasmakatalase wurde durch Milzquetschung nicht beeinflusst und nahm durch Infusion mit Leberbrei gemischten Erythrozytenbreis bei weitem weniger zu als nach Leberquetschung.

Auf Grund all meiner obigen Ergebnisse möchte ich hier als Todesursache bei auf Verletzung beruhender intraperitonealer Blutung, u. a. bei Leberverletzung, neben dem Blutverlust Folgendes ansehen : die infolge der Leberverletzung ausfliessende Galle wirkt ja auf das Blut hämolysierend; wenn sich dann die hämolysierte Blutmenge vermehrt und von der Blutbahn resorbiert wird, so tritt dazu noch intravaskuläre Hämolyse auf, und endlich kann nun die Giftigkeit dieses Hämoglobins den Tod verursachen. Dass das hämolysierte Blut in der Bauchhöhle schnell von der Blutbahn resorbiert wird, ist von Takizawa schon festgestellt worden, und die giftige Wirkung des Hämoglobins wurde auch von Ishizawa durch seine Versuche bewiesen. Von hier aus kann man wohl verstehen, wie bei Leberverletzung die innere Blutung, obwohl keine schwere Anämie eingetreten ist, den Tod verursacht. Der nach der Operation in der Bauchhöhle verbliebene Blutrest wirkt zwar nach meinen Versuchen, abgesehen von der bakteriellen Infektion, nicht so gefährlich, aber es wird m. E. sehr bedenklich, wenn man bei der Operation der Gallenblase versäumt, sich vor dem Auslaufen der Galle und auch schon vor geringer Blutung zu hüten; das scheint mir beachtenswert.

\section{Schluss.}

Alle obigen Ergebnisse zusammenfassend, möchte ich Folgendes sagen.

(1) Infusion von Erythrozytenbrei übt keinen Einfluss auf die Zu- oder Abnahme der Plasmakatalase aus. Deshalb scheinen die infundierten Erythrozyten im Körper des Empfängers nicht zerstört, sondern so, wie sie sind, resorbiert und dann benutzt zu werden.

(2) Infusion durch Mischung mit destilliertem Wassers oder mit Galle zum Teil aufgelösten Erythrozytenbreis ruft starke Zunahme der Plasmakatalase hervor. 
(3) Infolge innerer Blutung durch Quetschung eines intraperitonealen Organs nimint die Plasmakatalase zwar bei Leberverletzung sehr bedeutend, aber bei Milzverletzung gar nicht zu. M. E. lässt sich die Ursache dieser Zunahme auf den U̇bertritt der Organkatalase in die Blutbahn und die hämolytische Wirkung der Galle auf das ausgeflossene Blut zurückführen.

(4) Auf Grund meiner experimentellen Ergebnisse möchte ich bei innerer Blutung infolge von Leberverletzung es auch als Todesursache ansehen, dass das durch die ausgelaufene Galle hämolysierte Blut von der Blutbahn resorbiert wird und dann giftig wirkt.

Zum Schluss möchte ich auch hier meinem hochverehrten Lehrer, Herrn Prof. Dr. T. Is hikawa, meinen herzlichsten Dank für seine stets freundliche Führung und seine wertvollen Ratschläge aussprechen.

\section{Literatur.}

(1) Voge l. Dtsch. Ztschr. f. Chir., 1902, 63, 296.

(2) Irokaw a, Tokyo Igakkai Zasshi, 1914, 28, 187.

(3) Bröse, Zentralbl. f. Gyn., 1911, 38, 1339; Berl. kl. Wochenschr., 1912, 1743.

(4) Löwensteìn, Med. Klinik, 1911, 1773.

(5) Mackenrodt, zit. nach Bröse, Berl. kl. Wochenschr., 1912, 1743.

(6) Franz, zit, nach Bröse, do.

(7) Quincke, Dtsch. Arch. f. kl. Med., 1880, 27, 193.

(8) Takizaw a, Tohoku Journ. of Exp. Med, 1932, 18, 223 u. 512.

(9) Becht, Amer. Journ. of Physiol., 1919, 48, 171.

(10) van Thienen, Dtsch. Arch. f. kl. Med., 1920, 131, 113.

(11) 0 p penheimer, Die Fermente und ihre Wirkungen, Leipzig 1926, 5. Auf.

(12) $0 \mathrm{chi}$, Nippon Naikagakkai Zasshi, 1921, 9, 150; Hokkaido Igakkai Zasshi, $1928,6,722$.

(13) Kurokawa, Tohoku Journ. of Exp. Med., 1930, 14, 563.

(14) In o u e, Tokyo Igakkai Zasshi, 1920, 34, 1190.

(15) Yagi, Okayama Igakkai Zasshi, 1930, 42, 1044.

(16) H a suike, Okayama Igakkai Zasshi, 1928, 40, 659.

(17) Mats u no, Tohoku Journ. of Exp. Med., 1932, 14, 459.

(18) T a k a mu ra, Tokyo Igakkai Zasshi, 1922, 36, 218.

(19) Blue mel, Amer. Journ. of Physiol., 1921, 61, 464.

(20) Lazarus, Nothnage l: Specielle Pathologie u. Therapie, Bd. 8, Wien, 1906.

(21) Id o u. Suzuki, Fukuoka Ikadaigaku Zasshi, 1919, 12, 1.

(22) Milne, Dtsch. Areh. f. kl. Med., 1913, 109, 401.

(23) Rossius, Arch. f. kl. Chir., 1925, 137, 583.

(24) Nozaki, Chosen Igakkai Zasshi, 1929, 19, 1322.

(25) I t a mi u. Pratt, Biochem. Ztschr., 1909, 18, 302.

(26) S n a p per, Biochem. Ztsehr., 1912, 43, 256.

(27) S a k a i, Okayama Igakkai Zasshi, 1929, 41, 1353.

(28) Swjatskaja, Ztschr. f. d. ges. exp. Med., 1926, 52, 150. 
(29) Sattler, Fol. Haematol., 1910, 9, 216.

(30) Schustroff, Fol. Haematol., 1923, 29, 251.

(31) Date, Tokyo Igakkai Zasshi, 1928, 42, 1156.

(32) O k a, Jikken Igaku Zasshi, 1931, 15, 121.

(33) Y a ma moto, Nippon Biseibutsu-Gakkai Zasshi, 1926, 20, 1183.

(34) Viola u. Jona, Arch. de Physiol., 1895, 7, 37.

(35) . Otto, Dtsch. med. Wochenschr., 1921, 1550.

(36) I t a mi, Arch. f. exp. Pathol. u. Pharmak., 1909, 60, 76.

(37) Roberts o n, Journ. of Exp. Med., 1917, 26, 221.

(38) Od a, Nippon Naikagakkai Zasshi, 1923, 11, 952.

(39) Oczesalski a. Sterling, Arch.f. kl. Med., 1913, 109, 9.

(40) O no, Jikken Igaku Zasshi, 1926, 10, 629.

(41) B a rratt u. York, Ztschr. f. Immunitätsforsehung. 1912, 12, 333.

(42) It a mi, Arch. f. exp. Pathol, u. Pharmak., 1910, 62, 104.

(43) Rosenbaum, zit. n. Oppenheimer, Die Fermente und ihre Wirkungen, Leipzig 1926, 5. Anfl.

(44) Tuschtschenko, zit. n. Oppenheimer, do.

(45) J i n, Chosen Igakkai Zasshi, 1929, 19, 767.

(46) Ri, Chosen Igakkai Zasshi, 1929, 19, 1453.

(47) Takagi u. A i ba ra, Mitt. d. Med. Fakult. d. K. Univ. z. Tokyo, 1921, 27, 239.

(48) Vulpins, Beitr. z. kl. Chir., 1894, 11, 633.

(49) S c hulze, Beitr. z. kl. Chir., 1911, 74, 456.

(50) Hirschfeld u. We inert, Berl. kl. Wochenschr., 1914, 1026.

(51) N a ga n o, Tokyo Igakkai Zasshi, 1925, 39, 230.

(52) Bittner, Fol. Haematol., 1913, 1. Teil, Arch. 15, 237. 


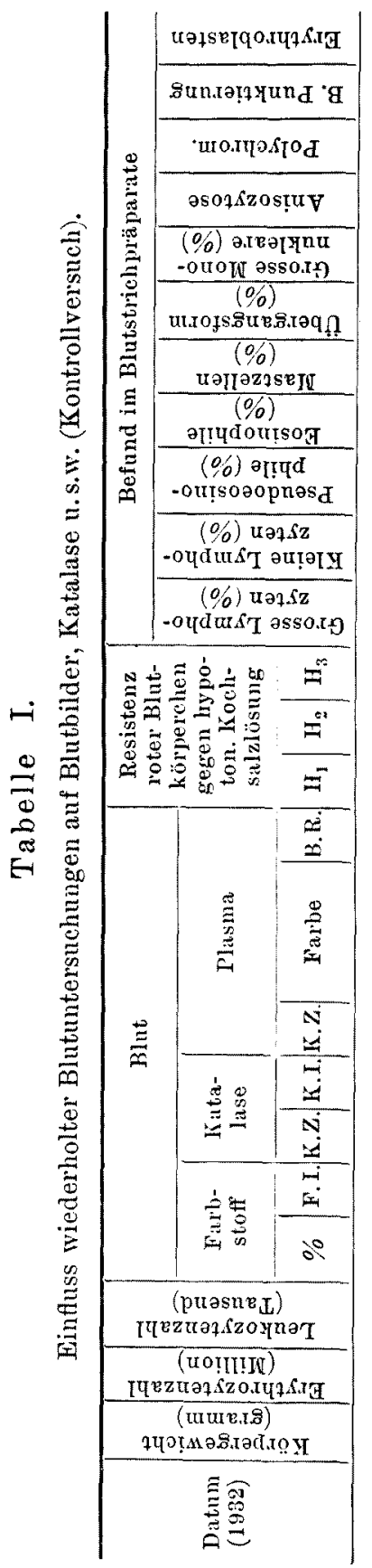

$\frac{1111111}{1111111} \frac{1 H H+H+H}{+H H+H+H}$

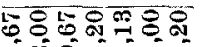

응

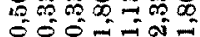

8808 앵명

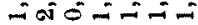

당앵ํำ

乌ूo:

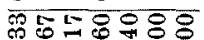

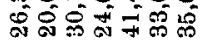

8850508

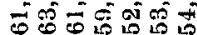

웅요 की $0=0$ जo 000

$\therefore$ б0 000000

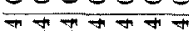

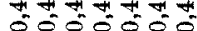
훙ㅇㅇ우응 0000000 1111111

I

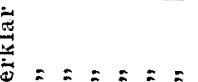
늘

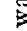

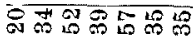

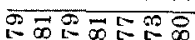

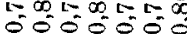

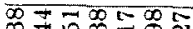

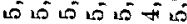

후용ㅇㅇ - = வழ シコシジニシ 궁ㅇㅇㅇㅇㅇㅇㅇㅇ $\infty \infty^{\infty} \infty=\infty \infty^{\infty}$

퓽ㅇㅇ

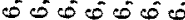
웅유용ㅇ

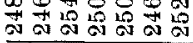

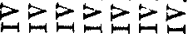
$\infty \dot{0} \dot{\theta}=\dot{0} \dot{0}$
1 1 1 1 1 1 1

| $111|1|$

1111111

1111111

응요맘연

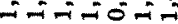

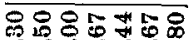
on $=100$ คे8 8 m

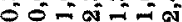

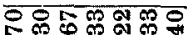
$0050-5$ 우융요요요

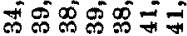
888 \%

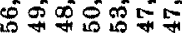

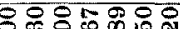
\$o $-\infty+\infty$ a 9800000 0 00 000 क क करण की 에

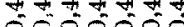
1111111<smiles>CCOCC</smiles>

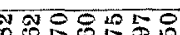

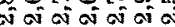

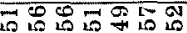
000000 항ㅇㅇㅇㅛ

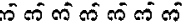

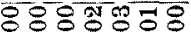
\%ᄋㅇㅇㅇㅠ 컹ㅇㅇ으응으. 은

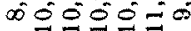

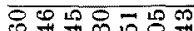
0́ 00 000000 $80888 \%$

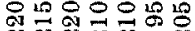

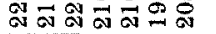
占包它它怘豆 किं

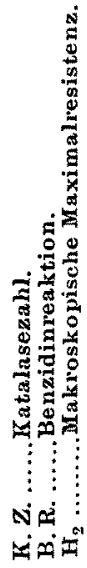

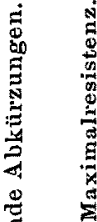
足 70 . on $\exists$. $+0$ क

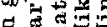
대출 $\circ$ 要 a $=20$ 孚 


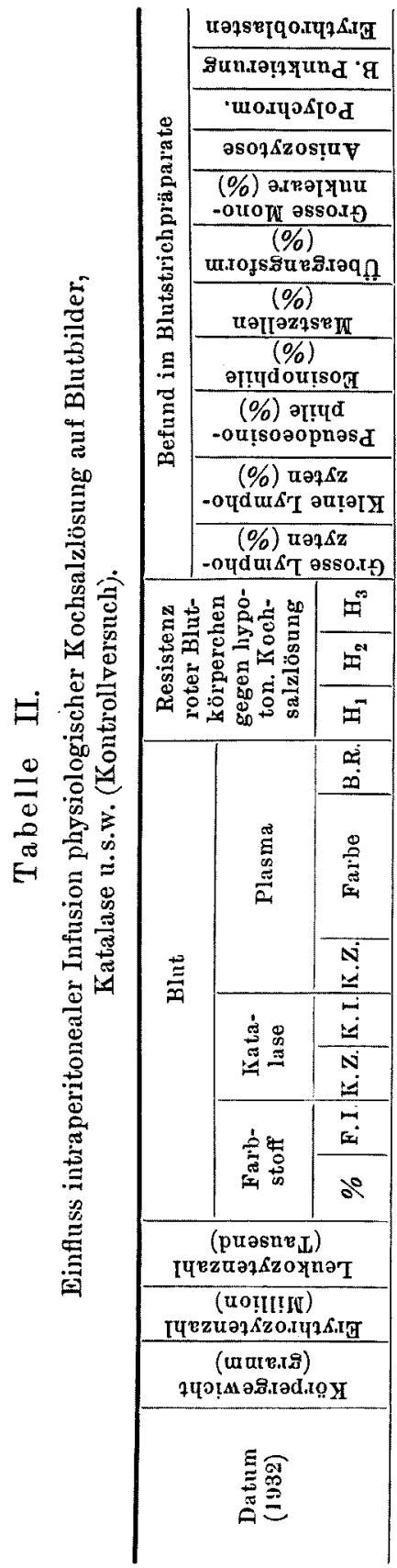

\begin{tabular}{|c|c|}
\hline 11 & 1111 \\
\hline 11 & 1111 \\
\hline+11 & $|H| 1$ \\
\hline+11 & $|H| 1$ \\
\hline $\begin{array}{l}\overline{8} \\
20 \\
0\end{array}$ & 웅 \\
\hline 5 & \% \\
\hline
\end{tabular}

\begin{tabular}{ccc}
$1+H$ & $H$ & $\mid H H$ \\
\hline 11 & 1 & 1
\end{tabular}

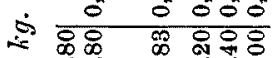

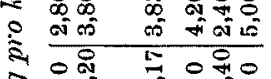

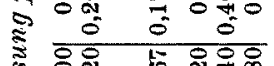

ठ유

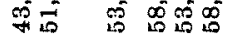

क्ष० :

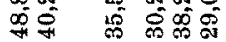

88 क

ذे

.

$\therefore$ की के क्ष

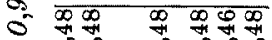

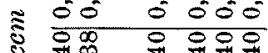

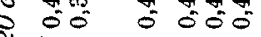

हूँ 11111

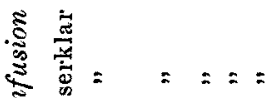

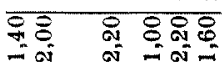

윰요용

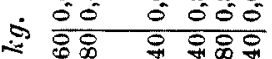

$\therefore$ तो को को

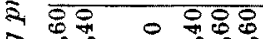

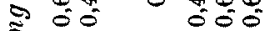

옹유 웅ㅇㅇㅇ

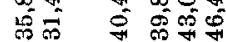

요 8 융주

की

요 웅ㅇㅇㅇ

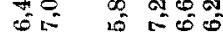

. 80 \%

i० 00 o 0

सु 可焉栾

$\Rightarrow$ ó ó 000

Dי

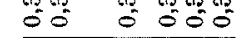

$\approx 111111$

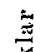

of

कान न

สำ

100 00 00

50 15 $8 \%$

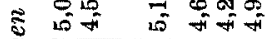

ㅇㅇㅇㅇㅇㅇㅇ

$\bar{i}=\vec{i}-\vec{i}-1$

స

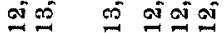

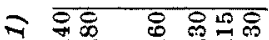

$\therefore \exists \equiv$ के बें की

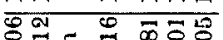

$\because=5 \div 00$

드요

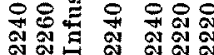

$=z==$

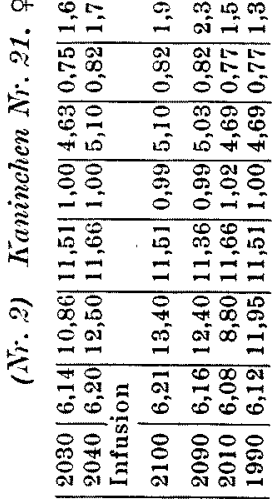

نx

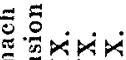

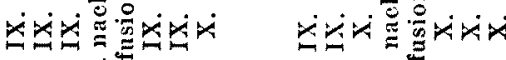

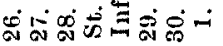

$$
-\dot{0}
$$

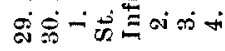



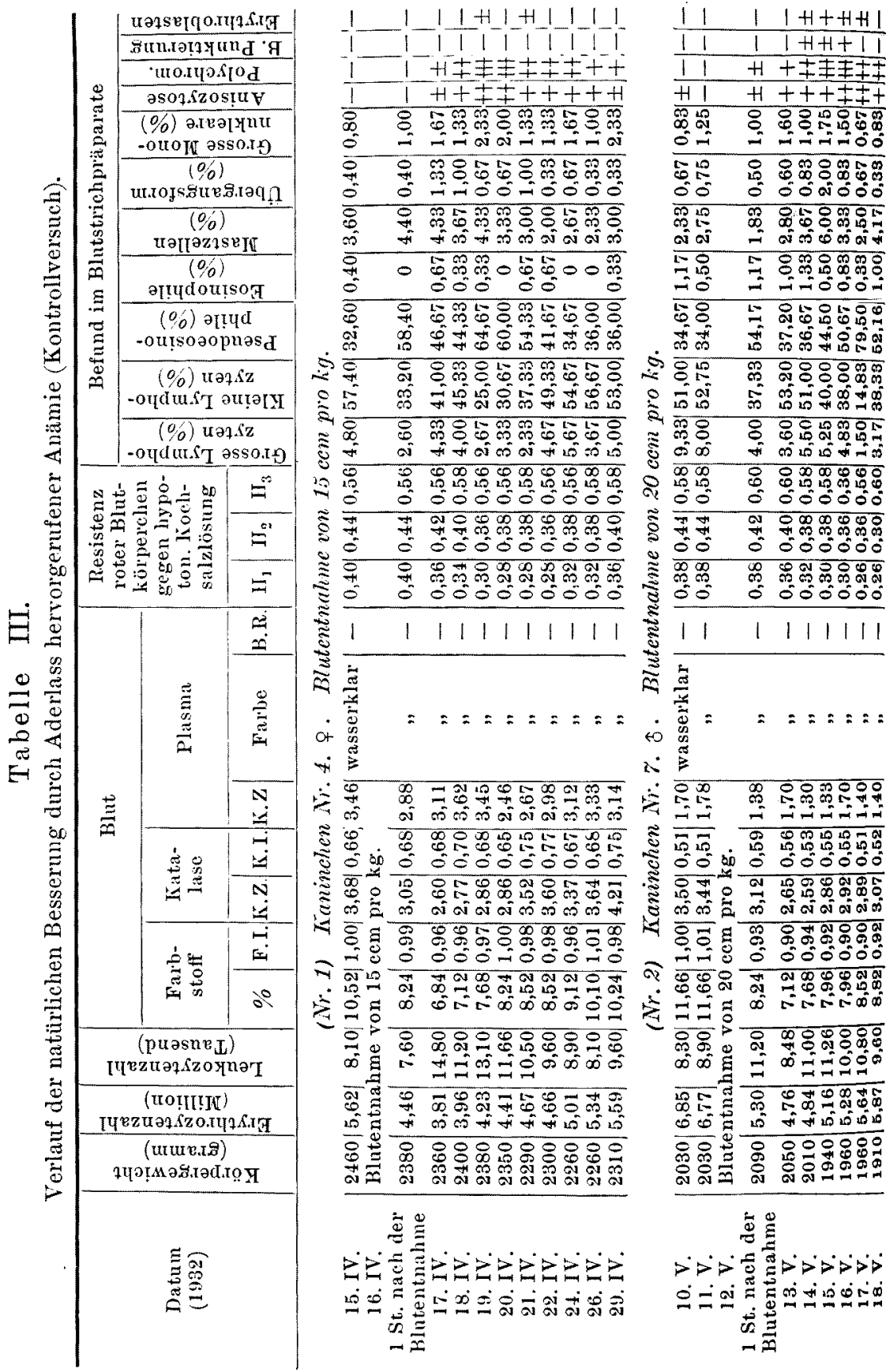

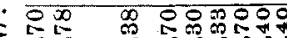

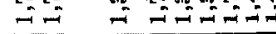

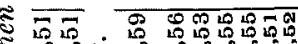

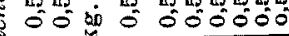

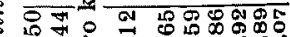

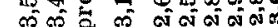

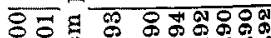

in o osojo:

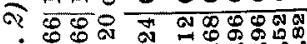

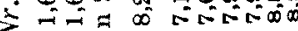
$\exists=$

요 \&

$\infty \infty^{\circ} \equiv \infty \exists=0$

ए人

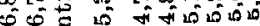

$00 \% 00000$

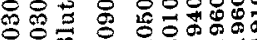

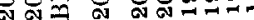

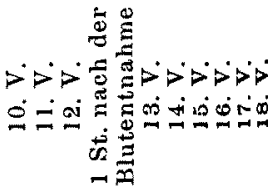


Utber die Todesursache bei innerer Verblutung infolge von Leberver]etzung 183

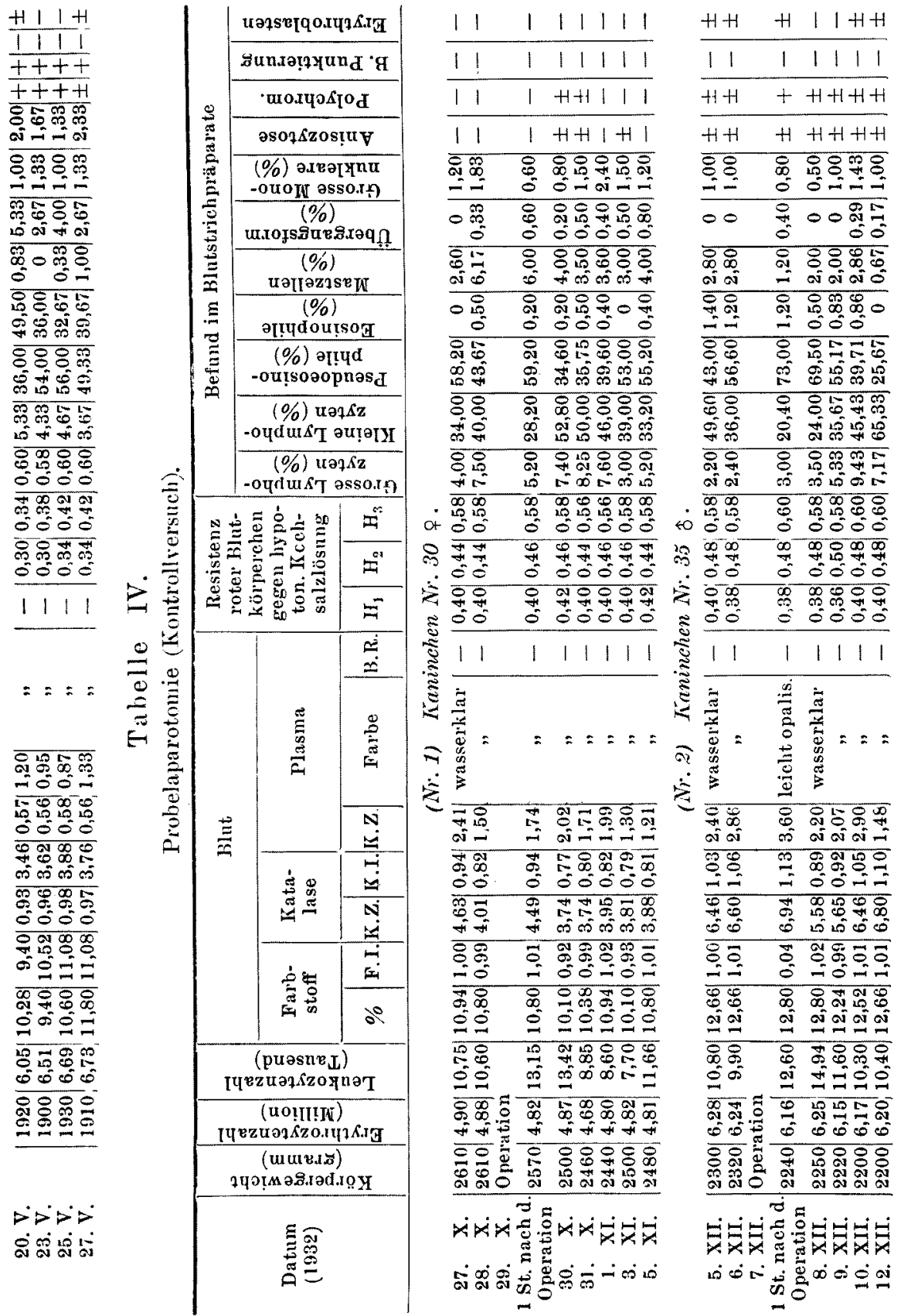




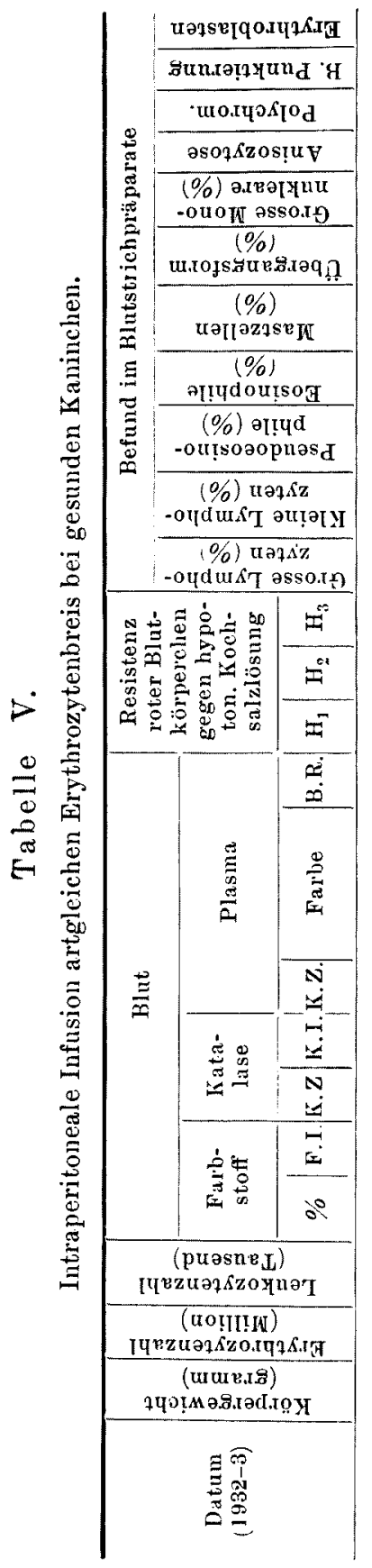

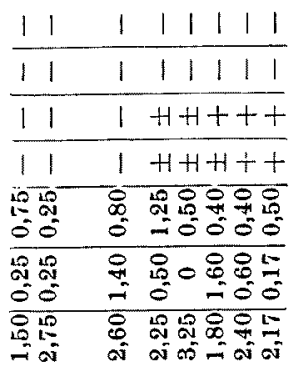

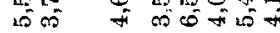

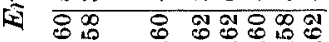
$\approx 00$ क 00000 \& $\infty$ - 000 영

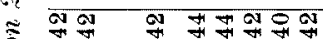
₹ 11 1 1 1 1 1

\begin{tabular}{|c|c|}
\hline 11 & $1111+$ \\
\hline 11 & 11111 \\
\hline$H H$ & $H \mid H H H$ \\
\hline & $H+H+H$ \\
\hline $\begin{array}{l}18 \\
8 \\
5\end{array}$ & 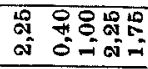 \\
\hline 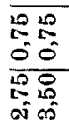 & 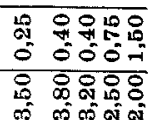 \\
\hline
\end{tabular}

$\dot{9}$

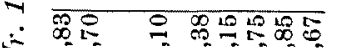
年 궁용 ड ०० 0 00000

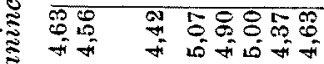

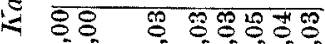
= $=1$

$78 \%$ क $80 \% 0 \%$

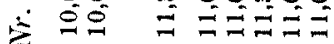

क्र 可

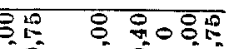

ऽ 둔

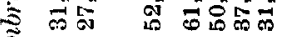

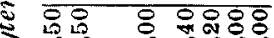

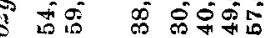

₹

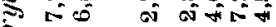

19 न

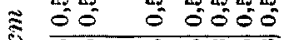

Oㅇ 000

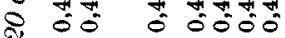

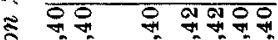

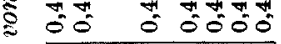

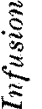

1111111

10

0 . 0 .

우용 $8 \%$ 용요

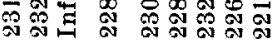

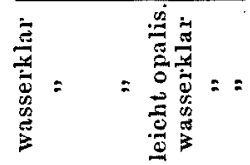

$\dot{2}$

क० 8 क्ण $8 \pi$

हैं की की की की

ร

०० 0 00

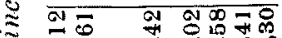

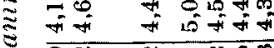

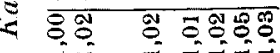

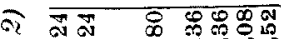

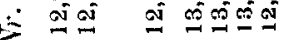

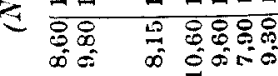

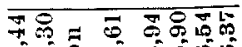

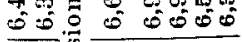

옹영 8 웅웅

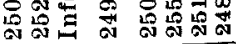

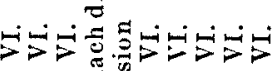

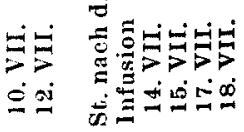

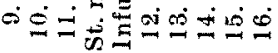




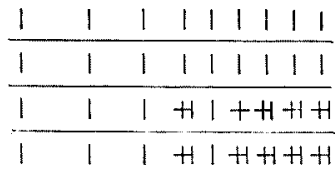
ह 8 o

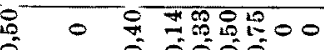

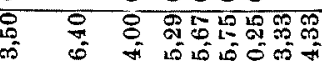
웅 8 \%

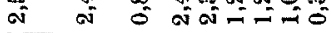
0 ? क क एक 0 एक 8 융

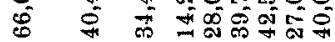
응 00 \%

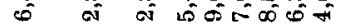

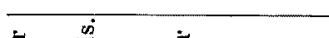

ot

㝏

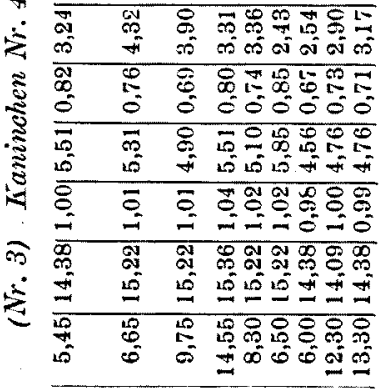

क

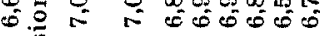

용

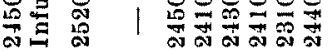

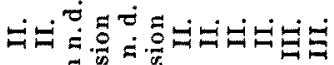

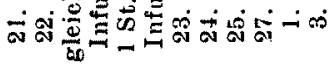

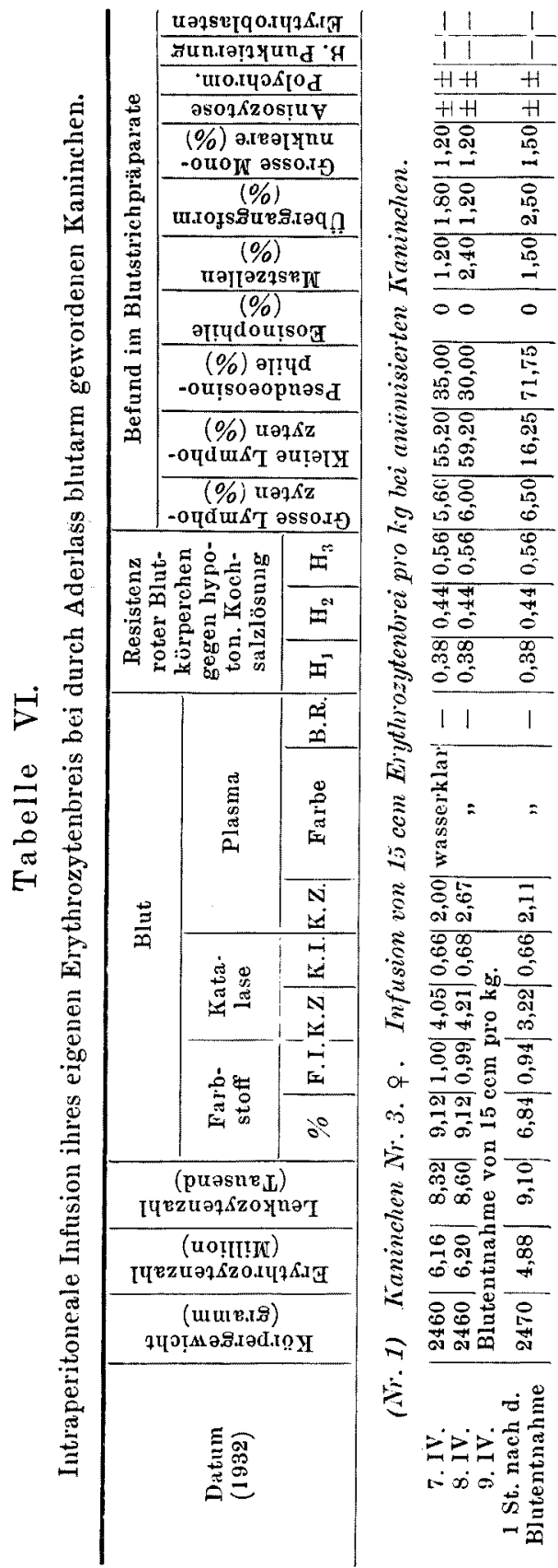




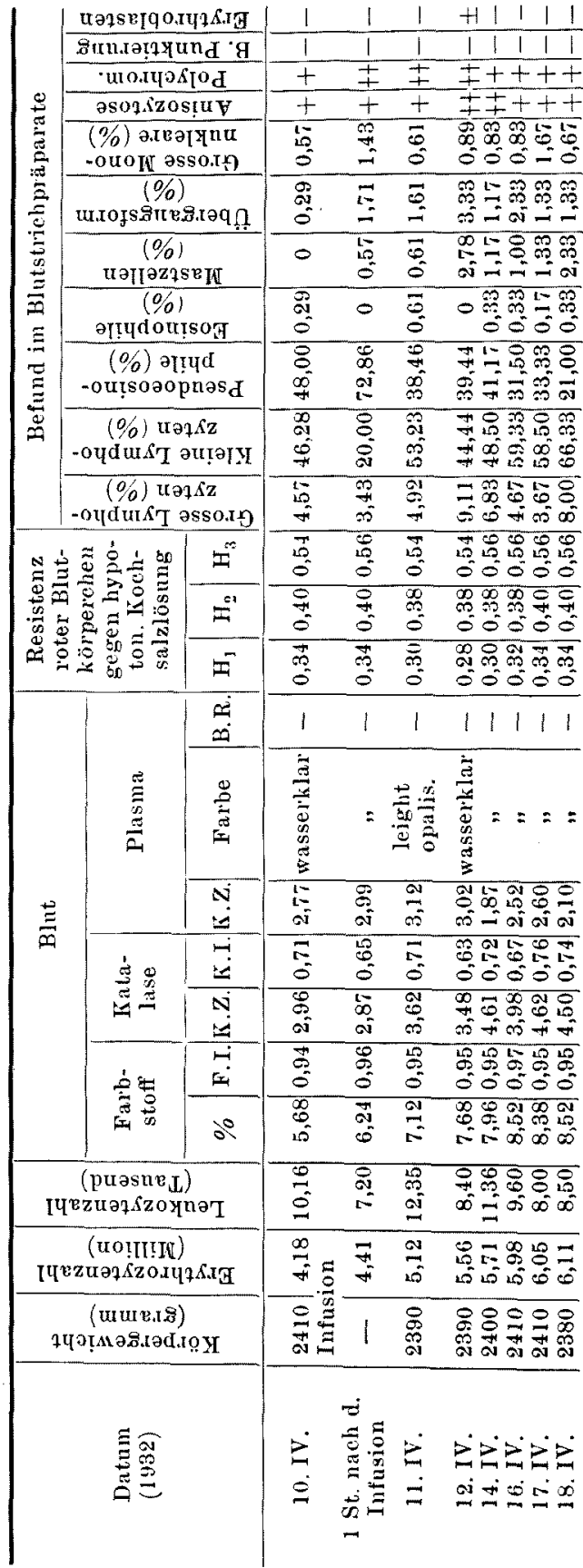

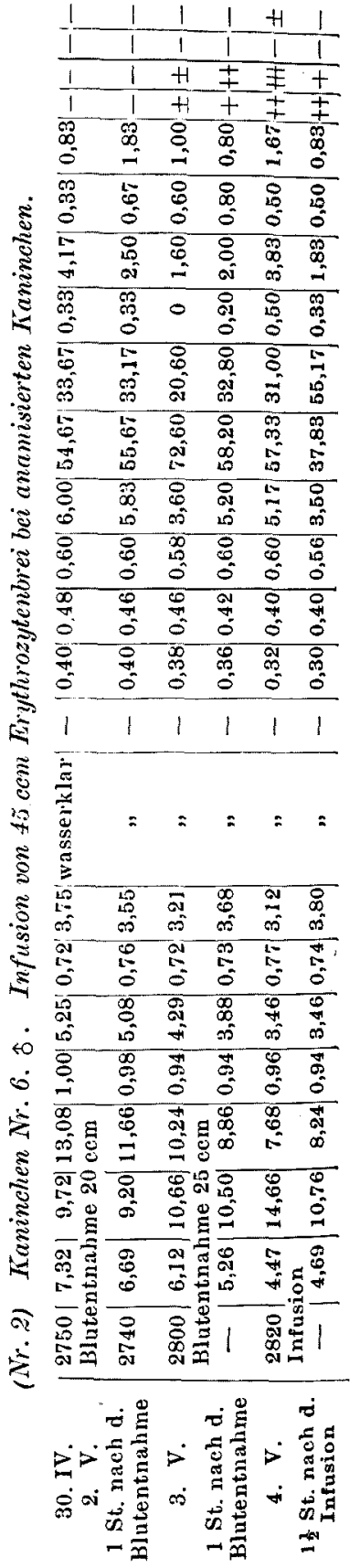




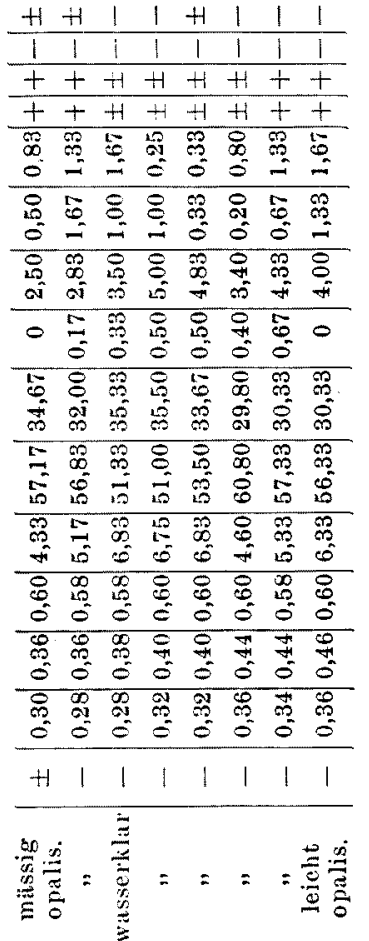

0280.98 यक

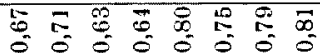

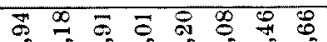

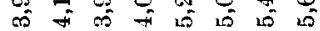

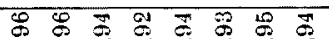
$=0$ o 0 o 0 o

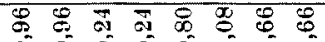

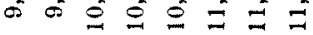
ह की की

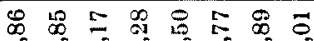

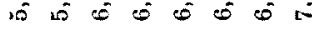

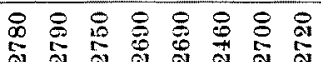

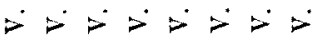

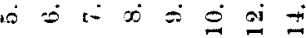

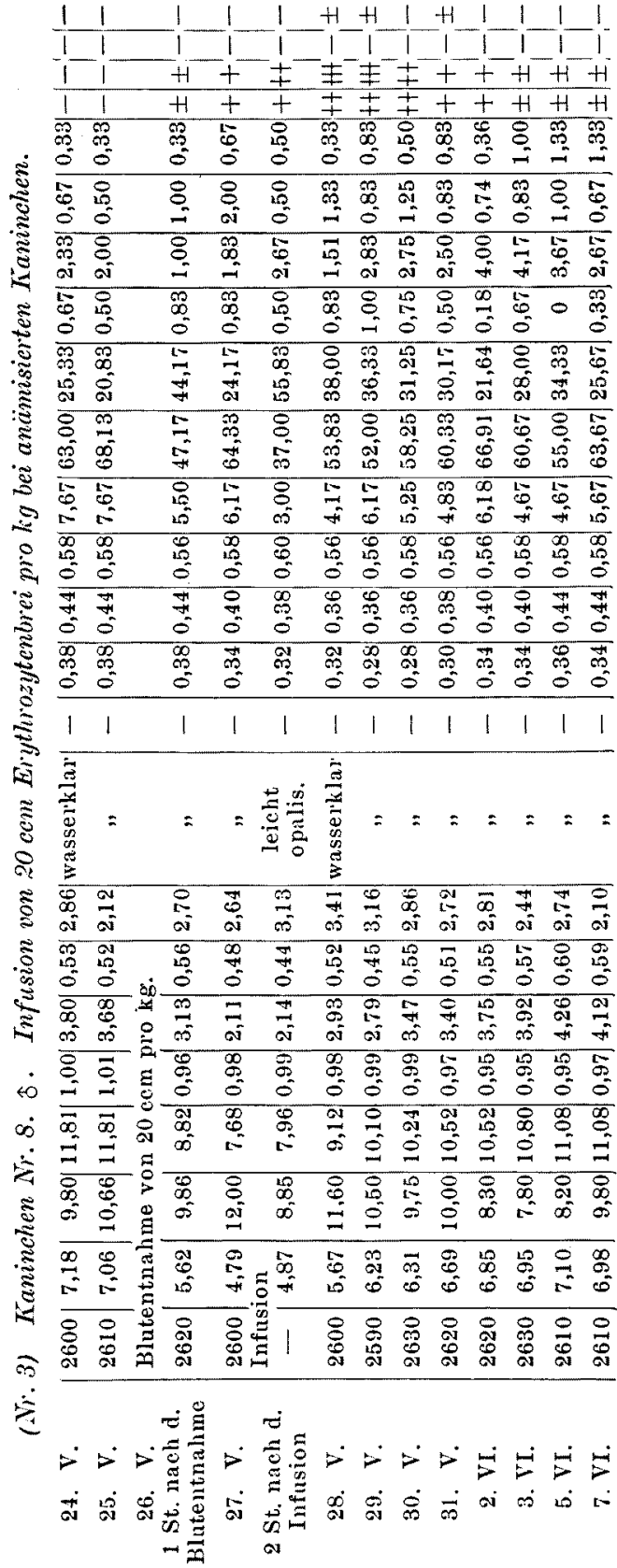




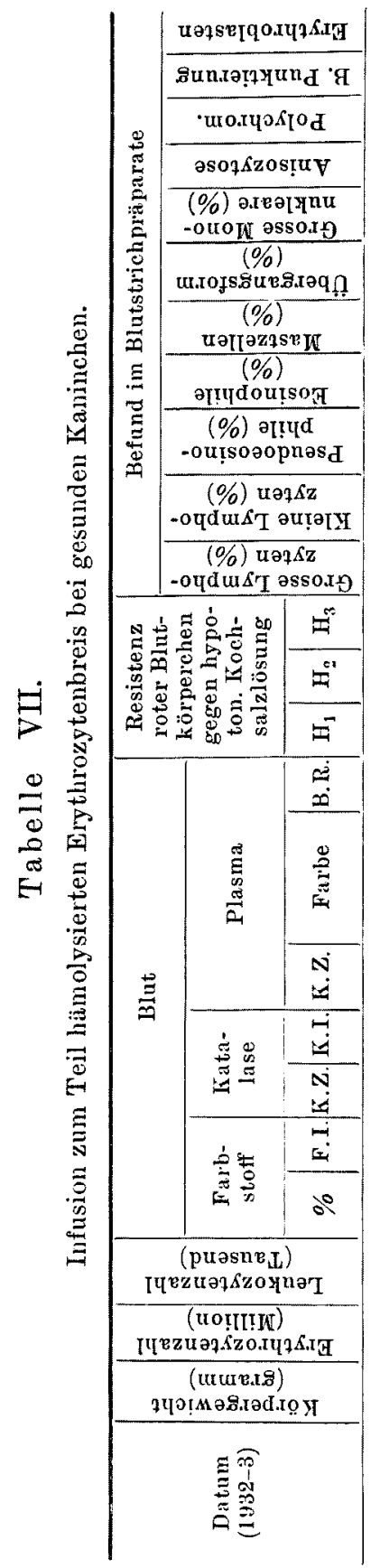

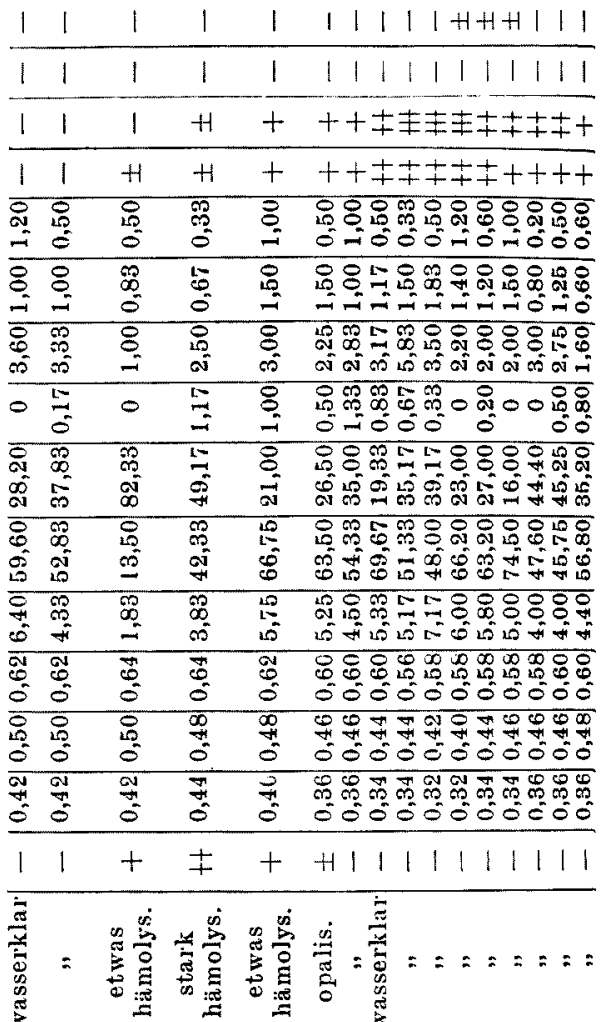

$\stackrel{5}{\stackrel{5}{\leftrightarrows}}$

매 की की की की

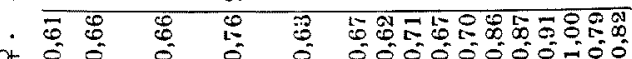

$\therefore$ 落

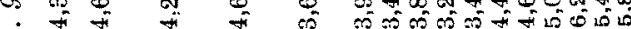

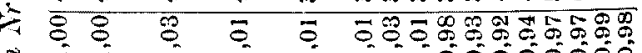

i $=-i=-1=0000000$

(

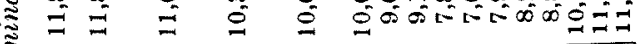

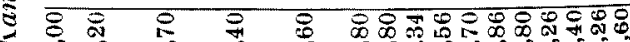
I

$\{\infty \%=$ क

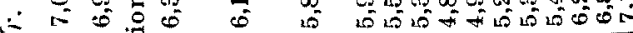

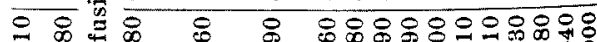

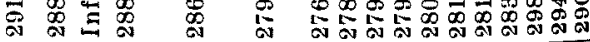

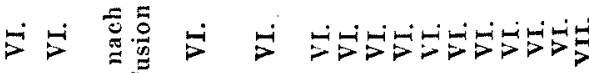

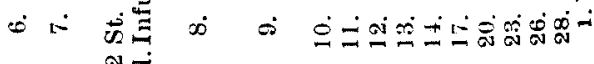


Über die Todesursache bei innerer Verblutung infolge von Lebeeverletzung 189

\begin{tabular}{llllllllllll}
1 & 1 & 1 & 1 & 1 & 1 & $1+H+H$ & +1 & 1 & 1 \\
\hline 1 & 1 & 1 & 1 & 1 & 1 & 1 & 1 & 1 & 1 & 1 & 1 \\
$H 1$ & 1 & + & + & +1 & $\pm \neq++$ & + & +
\end{tabular}

HI H H H +++++++

幽 8 용

용 \&

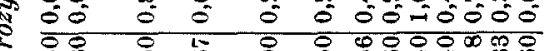

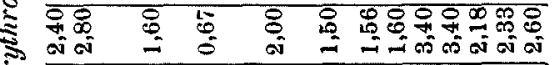
用 䓎。

₹

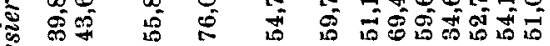
శ్

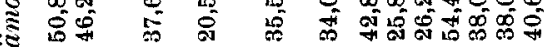
2 융 유

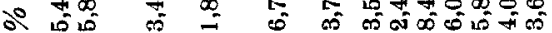

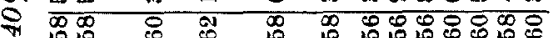

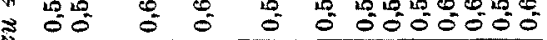

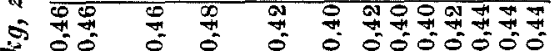
कू कू 制 密 $11+ \pm+11111111$ 요

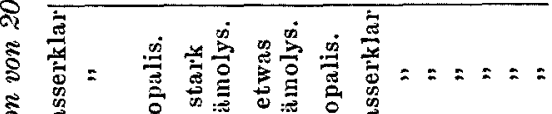
.ఃั

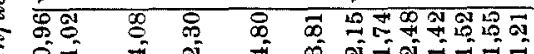
त

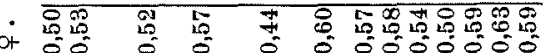
क कू

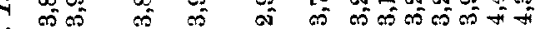

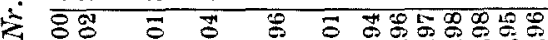

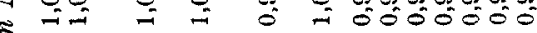

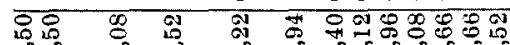
舟

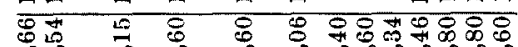

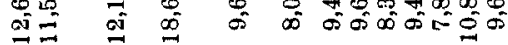

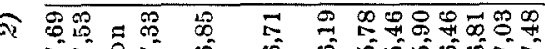
$\therefore 5=0$.

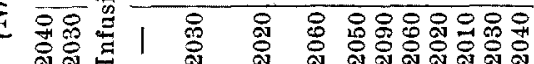
-

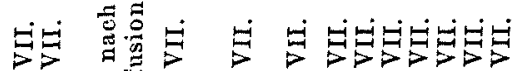

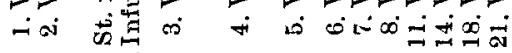

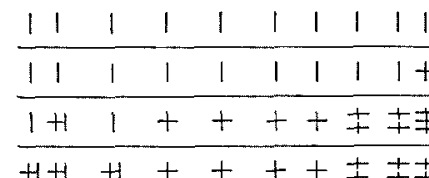

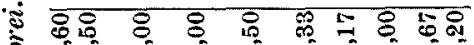

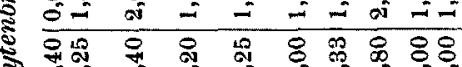

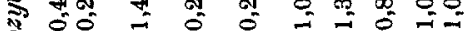
\%용 \& \& तิ क्ञ 응 ฐ व

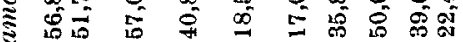

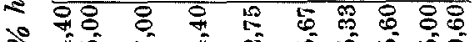

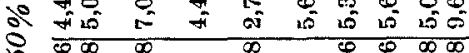

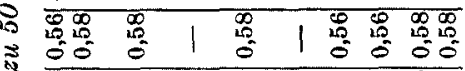

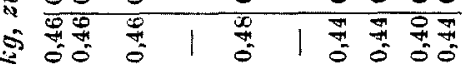
离员 今 $11+++++H 11$

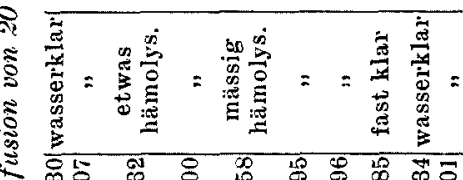

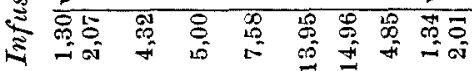

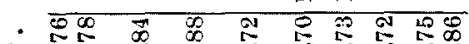
of 5:

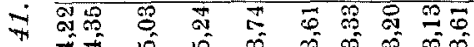

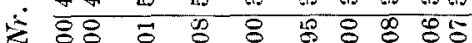

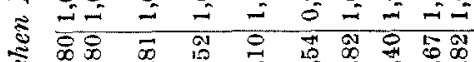

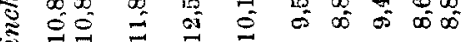

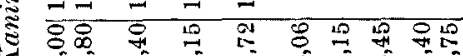

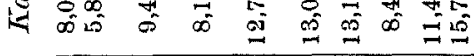

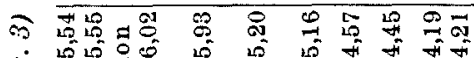

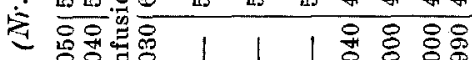

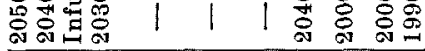

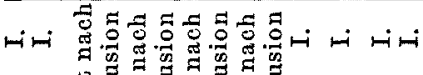

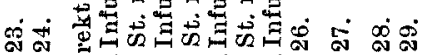

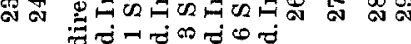




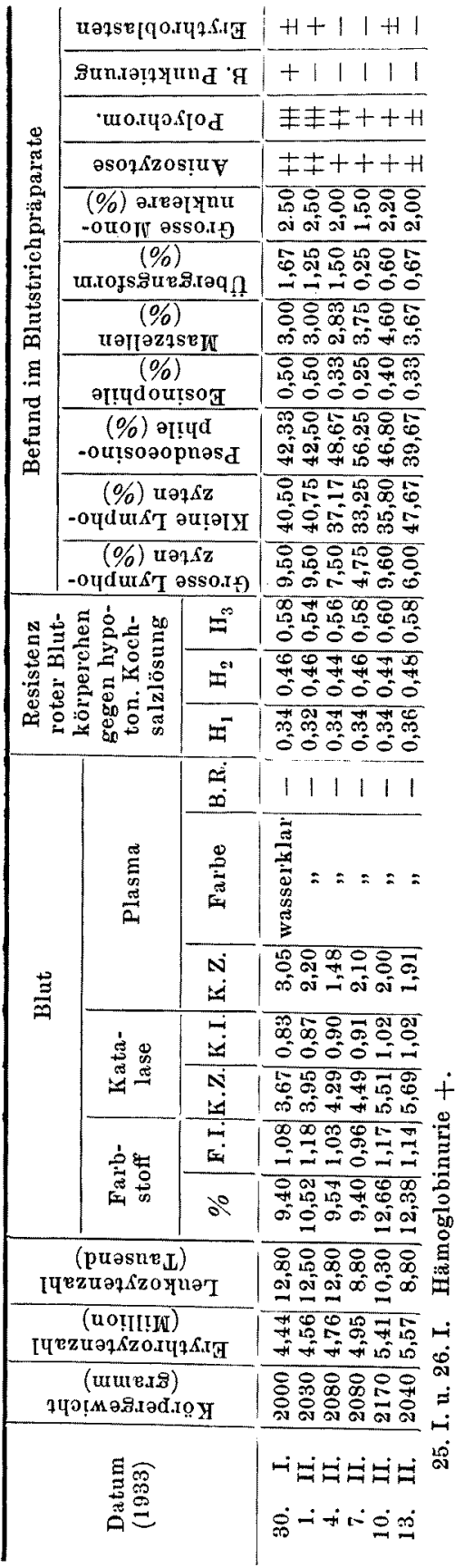

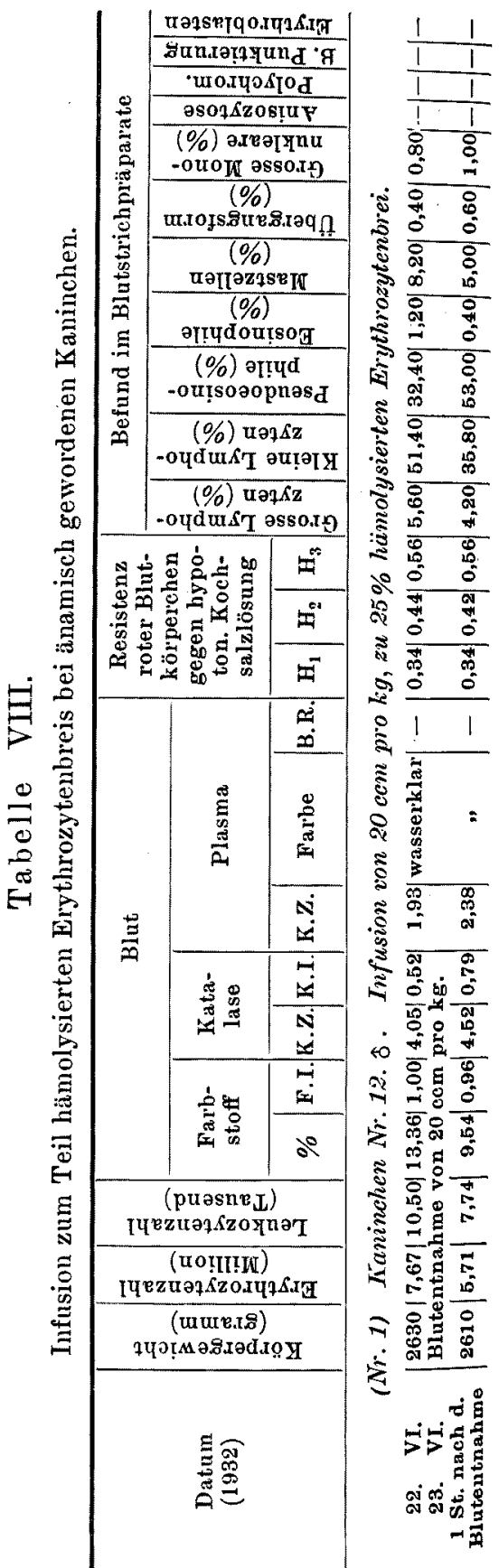




\begin{tabular}{|c|c|c|c|c|}
\hline 1 & 1 & H & 1 & 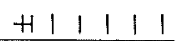 \\
\hline 1 & 1 & 1 & 1 & 11111111 \\
\hline$H$ & + & \pm & \pm & 主干+十+十 \\
\hline H & + & $t$ & $\mp$ & $\mp+\mathrm{H}+\mathrm{HH}$ \\
\hline בूּ & $\begin{array}{l}\infty \\
\infty \\
0 \\
0\end{array}$ & 8 & $\begin{array}{l}\infty \\
\infty \\
0 \\
0\end{array}$ & 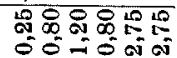 \\
\hline 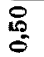 & ฐ্ণ & $\stackrel{20}{=}$ & 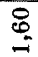 & 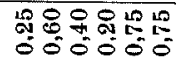 \\
\hline 年 & 8 & 荇 & 总 & 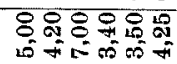 \\
\hline : & 总 & 0 & 웅 & 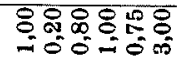 \\
\hline 究 & $\stackrel{8}{5}$ & $\begin{array}{l}0 \\
0 \\
010 \\
10\end{array}$ & న్ & 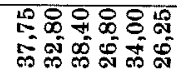 \\
\hline 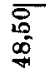 & $\begin{array}{l}\text { if } \\
\text { ât }\end{array}$ & $\begin{array}{l}8 \\
10 \\
00^{\circ} \\
\text { m }\end{array}$ & 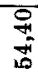 & 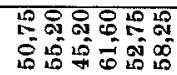 \\
\hline 要 & 8 & 5 & 엉 & 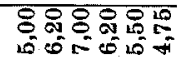 \\
\hline $\begin{array}{l}\text { DI } \\
\text { 20 } \\
0\end{array}$ & $\begin{array}{l}0 \\
100 \\
-10\end{array}$ & $\begin{array}{l}00 \\
0 \\
0\end{array}$ & $\begin{array}{l}00 \\
0 \\
8 \\
8\end{array}$ & 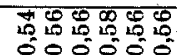 \\
\hline $\begin{array}{l}\text { a } \\
0 \\
0\end{array}$ & If & :- & - & 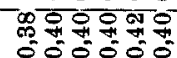 \\
\hline 高 & 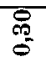 & 兽 & 我 & 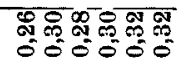 \\
\hline I & 1 & + & + & 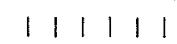 \\
\hline
\end{tabular}

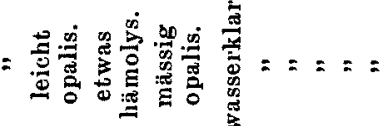
我

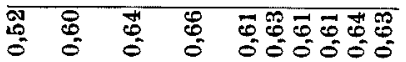
突

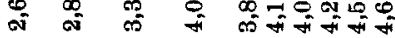

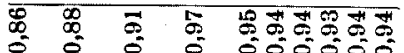

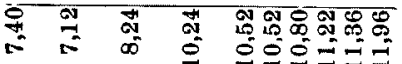

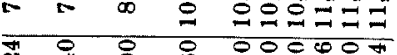

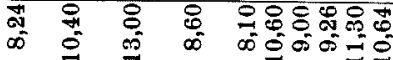

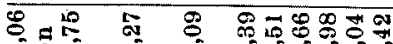
i.

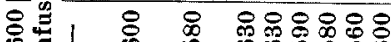
惫声

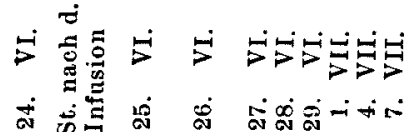

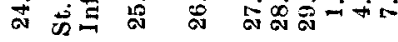

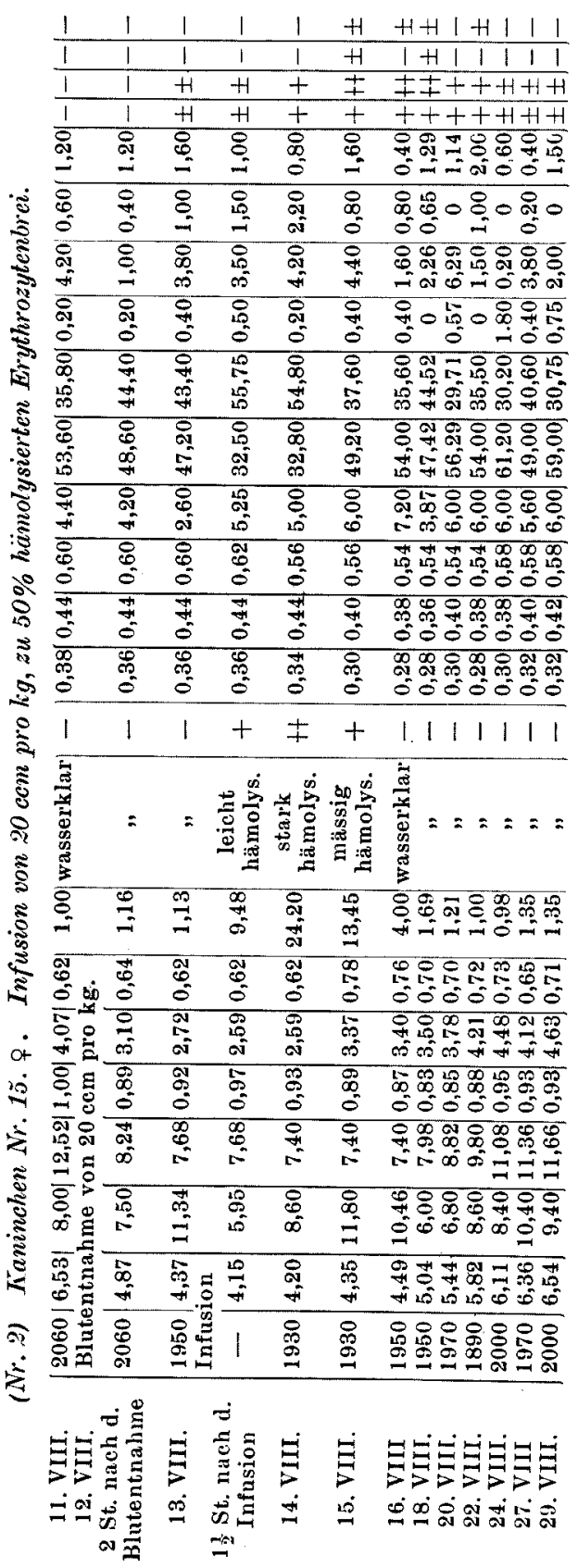




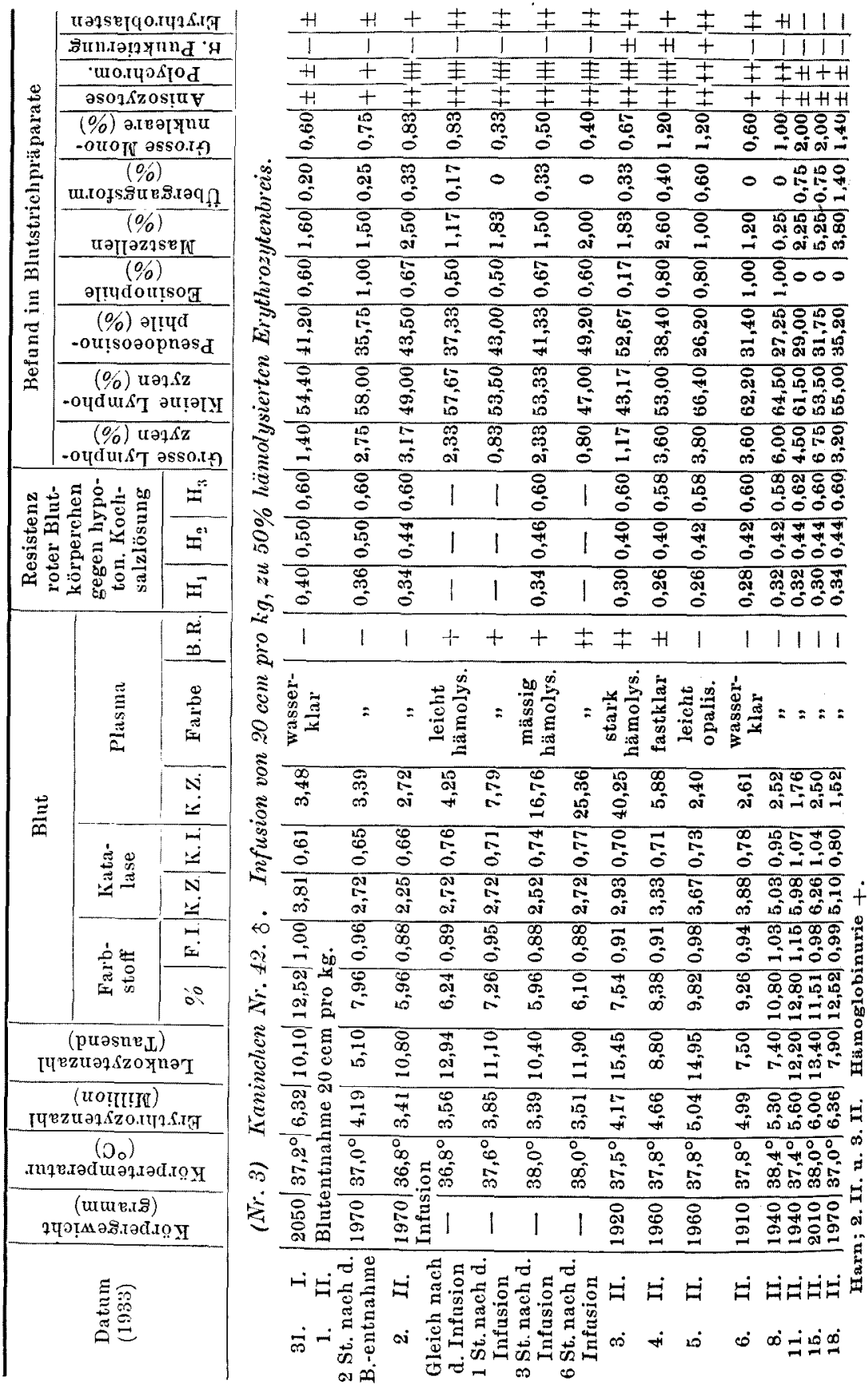




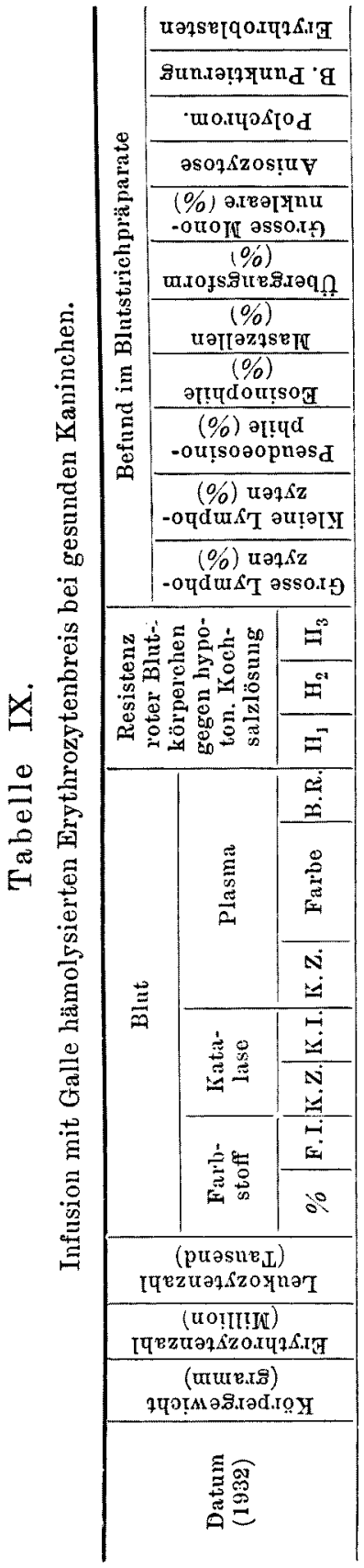

\begin{tabular}{|c|c|c|c|c|c|c|}
\hline & & & † & $1+1$ & $H$ & - 111 \\
\hline & 1 & 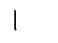 & 1 & $H H$ & H & $H \neq 111$ \\
\hline & 1 & 1 & $+H$ & $\ddagger \neq$ & $\equiv$ & 夆主士十+ \\
\hline & 1 & I & + & $\mp \mp$ & $\mp$ & $\mp \mp++H+H$ \\
\hline & & 学 & $\begin{array}{l}8 \\
8 \\
0\end{array}$ & $\begin{array}{l}8 \\
0 \\
=\end{array}$ & 产 & $\begin{array}{l}8 \\
\Xi \\
=\end{array}$ \\
\hline & 8 & & : & $\begin{array}{ll}0 & 0 \\
0 & 5 \\
0 & 0 \\
0 & -0\end{array}$ & 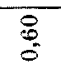 & $g_{0}^{8} 8080$ \\
\hline & & 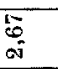 & â & $\begin{array}{ll}8 & 8 \\
\text { s } & 0 \\
\end{array}$ & $\stackrel{8}{-1}$ & 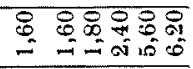 \\
\hline & & 带 & 告 & 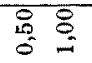 & $\frac{9}{0}$ & 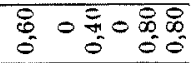 \\
\hline & $\begin{array}{l}\text { D. } \\
\text { a } \\
\text { a }\end{array}$ & 品 & 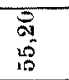 & 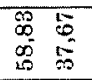 & 焉 & 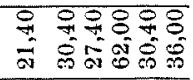 \\
\hline & 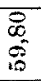 & $\begin{array}{l}5 \\
8 \\
00 \\
10\end{array}$ & 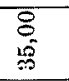 & 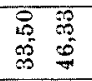 & 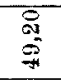 & 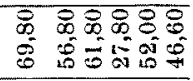 \\
\hline & ơ & 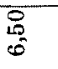 & 8 & $\begin{array}{ll}5 & 5 \\
6 & 5 \\
\infty & 0\end{array}$ & $\begin{array}{l}\infty \\
\infty \\
\infty\end{array}$ & 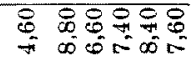 \\
\hline & & $\begin{array}{l}18 \\
18 \\
0\end{array}$ & : & 要 & 粕 & 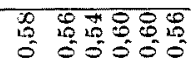 \\
\hline & $\begin{array}{l}\text { क्ष } \\
\text { से } \\
0\end{array}$ & $\frac{\infty}{1}$ & & & 总 & 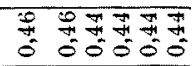 \\
\hline & 8 & : & 紊 & $\begin{array}{l}7 \\
7 \\
0 \\
0\end{array}$ & 总 & 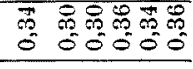 \\
\hline & 1 & 1 & $\mp$ & $\neq \pm$ & + & 111111 \\
\hline & & & 我禹 & 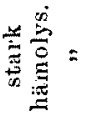 & $\stackrel{3}{\stackrel{n}{3}}$ & \\
\hline & $\begin{array}{l}8 \\
8 \\
\text { es }\end{array}$ & & $\begin{array}{l}80 \\
6 \\
0\end{array}$ & 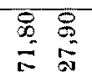 & $\stackrel{\infty}{N}$ & 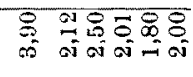 \\
\hline & 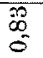 & 这 & $\begin{array}{l}20 \\
0 \\
0\end{array}$ & $\begin{array}{ll}\infty & 0 \\
0 & 0 \\
0 & 0 \\
0\end{array}$ & $\begin{array}{l}\infty \\
0 \\
0\end{array}$ & $\begin{array}{l}\bar{\infty}= \\
0 \\
0 \\
0\end{array}$ \\
\hline & $\begin{array}{l}\mathscr{M} \\
\substack{\infty \\
\text { fi }}\end{array}$ & 量 & $\begin{array}{ll}2 \\
\infty \\
\infty \\
0\end{array}$ & 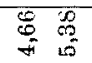 & $\underset{c}{\infty}$ & 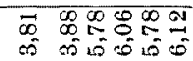 \\
\hline & 8 & $\Xi$ & $\stackrel{9}{0}$ & $\stackrel{a}{=}=$ & 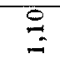 & $\stackrel{20}{\Rightarrow}=0050$ \\
\hline & : & $\begin{array}{l}\infty \\
0 \\
\infty \\
\infty\end{array}$ & $\stackrel{\infty}{\infty}$ & $\begin{array}{ll}0 \\
0 \\
0 \\
0 \\
0\end{array}$ & 点 & 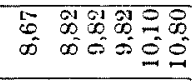 \\
\hline & & $\begin{array}{l}\mathscr{\infty} \\
\infty \\
\infty\end{array}$ & to & 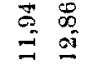 & $\begin{array}{l}\widehat{\Xi} \\
\infty \\
\infty\end{array}$ & 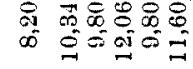 \\
\hline & $\overline{\mathscr{C}}$ & S: & $\begin{array}{l}\infty \\
0 \\
0 \\
0\end{array}$ & $\begin{array}{ll}9 \\
0 & 58 \\
5 & 5 \\
0\end{array}$ & $\begin{array}{l}8 \\
8 \\
-7\end{array}$ & 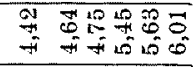 \\
\hline & & 8 & 요 & 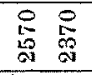 & $\begin{array}{l}\text { 昜 } \\
\text { 品 }\end{array}$ & 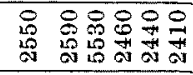 \\
\hline & & & 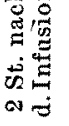 & 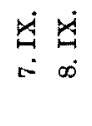 & 虫 & \\
\hline
\end{tabular}



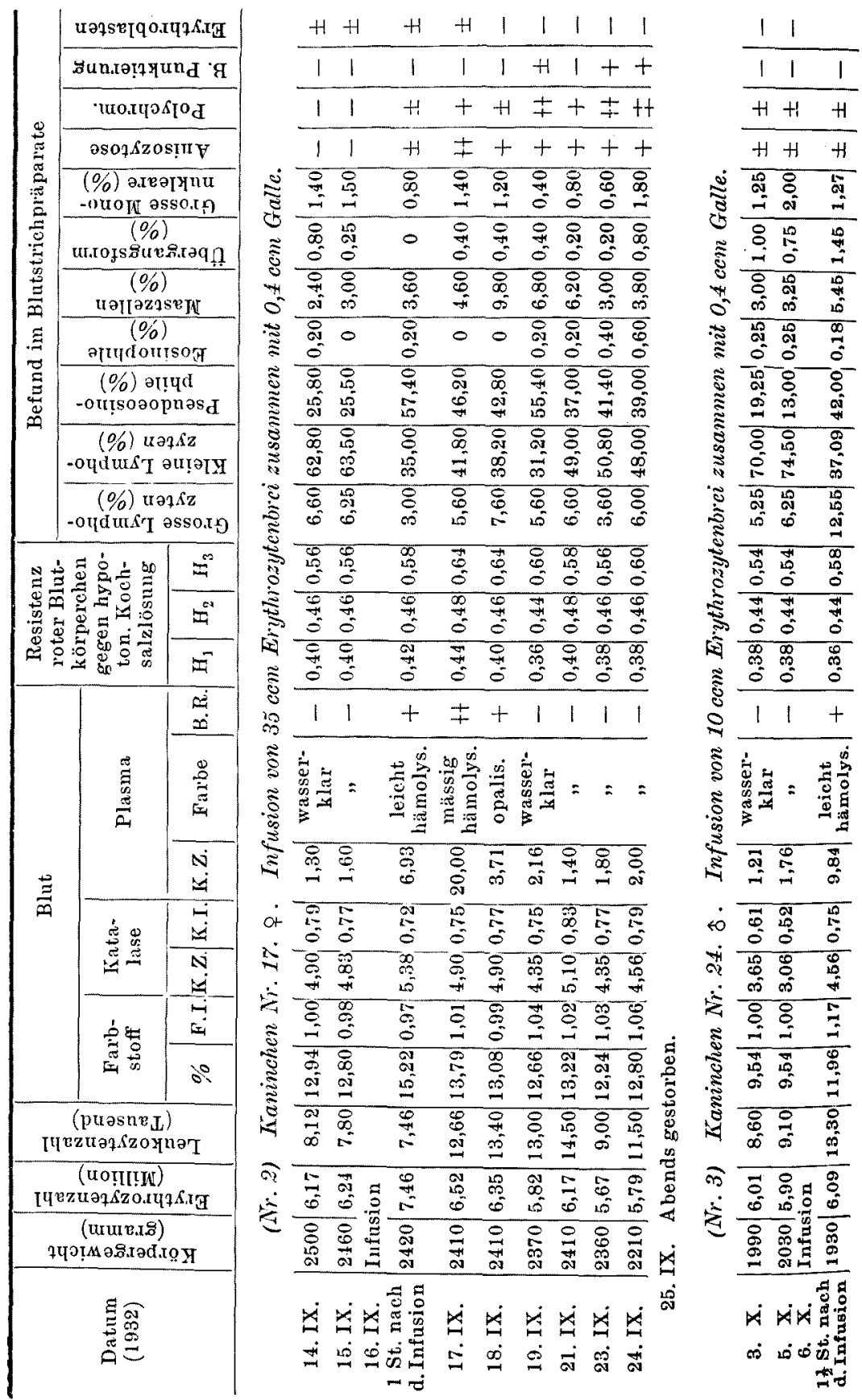


\begin{tabular}{|c|c|c|c|c|c|c|c|}
\hline$\mp$ & \pm & $\mp$ & \pm & $H$ & $H$ & 1 & 17 \\
\hline$\mp$ & $\mp$ & $\mp$ & $\mp$ & $\neq$ & $\mp$ & + & + \\
\hline+ & $H$ & + & + & + & + & + & + \\
\hline $\begin{array}{l}5 \\
0 \\
0 \\
0\end{array}$ & $\stackrel{8}{8}$ & $\stackrel{8}{8}$ & 언 & $\underset{\pi}{m}$ & $\underset{0}{8}$ & $\stackrel{8}{\circ}$ & $\stackrel{P}{=}$ \\
\hline 留 & 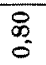 & త్ & 0 & is & $\begin{array}{l}8 \\
0 \\
0\end{array}$ & 0 & 里 \\
\hline 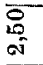 & $\begin{array}{l}\infty \\
\infty \\
\text { N }\end{array}$ & $\begin{array}{l}8 \\
\text { \& } \\
\text { की }\end{array}$ & 总 & $\begin{array}{l}\mathscr{D}^{\circ} \\
25\end{array}$ & $\begin{array}{l}8 \\
0 \\
6\end{array}$ & $\begin{array}{l}8 \\
6 \\
\infty\end{array}$ & $\begin{array}{l}8 \\
10^{-}\end{array}$ \\
\hline$\overline{0}$ & $\begin{array}{l}\text { 年 } \\
\text { - }\end{array}$ & 0 & 0 & 0 & 0 & 0 & 용 \\
\hline $\begin{array}{l}\text { 응 } \\
\text { ơ }\end{array}$ & $\begin{array}{l}8 \\
\stackrel{0}{0} \\
\infty \\
\rightarrow\end{array}$ & $\begin{array}{l}0 \\
\infty \\
0 \\
0 \\
0\end{array}$ & $\begin{array}{l}0 \\
\text { on } \\
0 \\
0\end{array}$ & $\stackrel{\infty}{\stackrel{\infty}{\infty}}$ & $\stackrel{5}{10}$ & $\frac{8}{5}$ & $\begin{array}{l}0 \\
\text { on } \\
\infty \\
\infty\end{array}$ \\
\hline 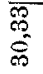 & $\begin{array}{l}8 \\
7 \\
7\end{array}$ & $\begin{array}{c}9 \\
80 \\
08\end{array}$ & $\underset{\delta}{8}$ & $\begin{array}{l}0 \\
\infty \\
\neq \\
\neq\end{array}$ & $\begin{array}{l}8 \\
0 \\
0\end{array}$ & $\begin{array}{l}8 \\
8 \\
00 \\
0 \\
0\end{array}$ & $\begin{array}{c}8 \\
0 \\
0 \\
0\end{array}$ \\
\hline 8 & $\begin{array}{l}\text { ô } \\
\text { f }\end{array}$ & $\begin{array}{l}8 \\
0 \\
\infty\end{array}$ & 8 & $\begin{array}{l}\mathscr{D} \\
\infty \\
=\end{array}$ & $\begin{array}{l}\infty \\
m \\
0 \\
0 \\
0\end{array}$ & $\begin{array}{l}0 \\
0 \\
\text { o }\end{array}$ & $\underset{\mathbb{N}}{\mathbb{N}}$ \\
\hline $\begin{array}{l}5 \\
0 \\
0 \\
0\end{array}$ & $\begin{array}{l}\mathbb{Y} \\
0 \\
0\end{array}$ & $\begin{array}{l}8 \\
8\end{array}$ & $\begin{array}{l}\infty \\
10 \\
0 \\
0\end{array}$ & $\begin{array}{l}0 \\
0 \\
0 \\
0\end{array}$ & : & $\begin{array}{l}\overrightarrow{7} \\
5 \\
0\end{array}$ & \\
\hline \& & 禺 & 离 & 영 & 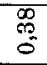 & 啇 & $\begin{array}{l}\stackrel{8}{+1} \\
0\end{array}$ & $\frac{8}{4}$ \\
\hline $\begin{array}{l}\bar{\infty} \\
\stackrel{2}{0} \\
0\end{array}$ & $\begin{array}{l}\infty \\
\infty \\
0 \\
0\end{array}$ & $\begin{array}{l}0 \\
0 \\
0 \\
0\end{array}$ & \begin{tabular}{l}
$\infty$ \\
\multirow{N}{*}{} \\
0
\end{tabular} & $\begin{array}{l}\text { @ } \\
\stackrel{N}{0}\end{array}$ & $\begin{array}{l}\infty \\
\stackrel{2}{0} \\
0\end{array}$ & 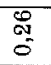 & \\
\hline & 1 & 1 & 1 & 1 & 1 & 1 & 1 \\
\hline
\end{tabular}

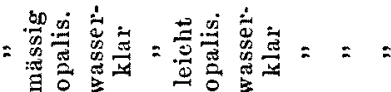

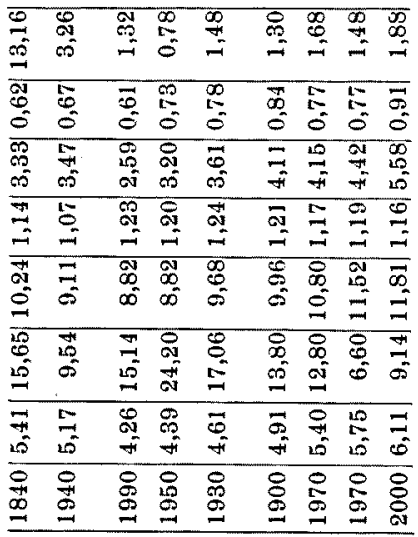

$\dot{4} \dot{4} \dot{x} \dot{4} \dot{A} \dot{x} \dot{x} \dot{x}$

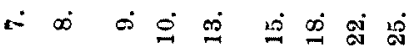

\begin{tabular}{lllllllllll}
1 & 1 & 1 & $H$ & 1 & 1 & 1 & $H$ & 1 & 1 & 1 \\
\hline 1 & 1 & 1 & 1 & $H$ & $H$ & + & + & 1 & 1 & 1 \\
\hline & 1 & $H$ & $H$ & + & $H$ & + & + & + & $+H$ \\
\hline & 1 & + & + & + & + & + & + & + & + & $H$ \\
\hline & 0 & 0 & + & 0 & 0 & 0 & 0 & 0 & 0
\end{tabular}
苛 ए 8 유

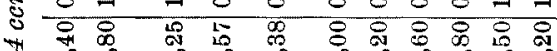

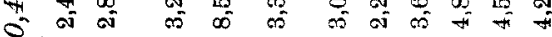

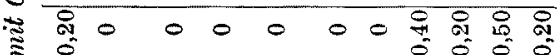
용 8 a जी की

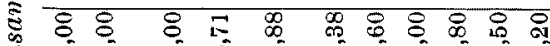
范

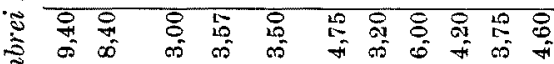

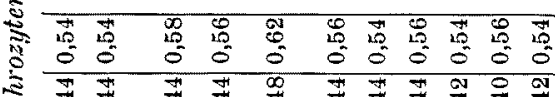

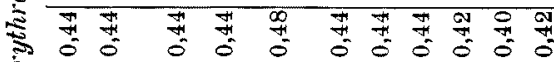
जिए फ़ की

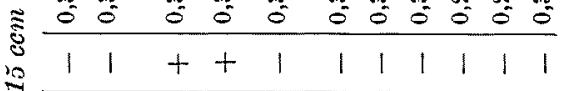

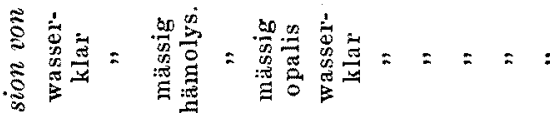

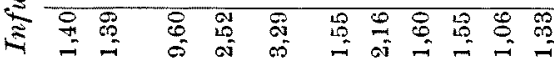

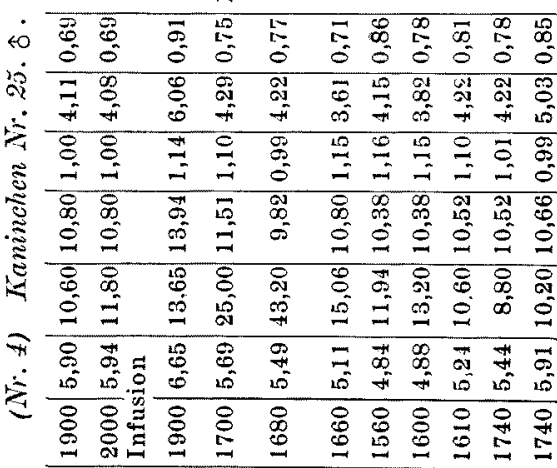

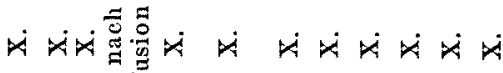
هi 


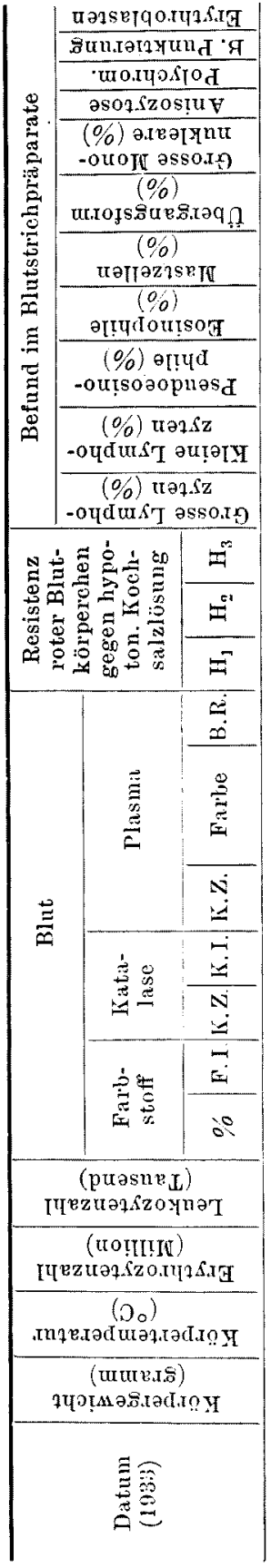

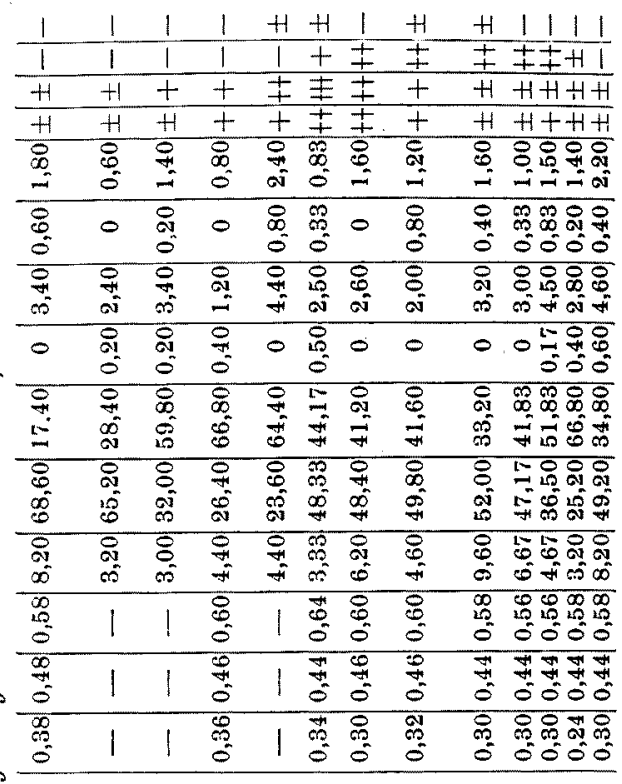

守 $1++\mp \pm \pm \mp+111111$

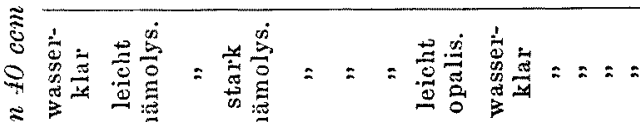

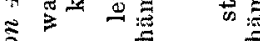

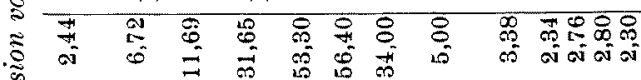<smiles>[Li][13CH3]</smiles>
倍

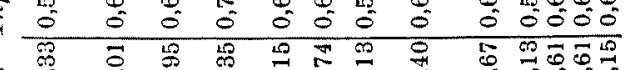

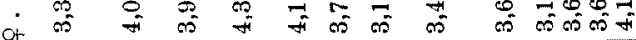

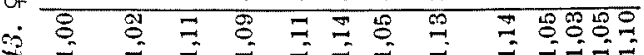

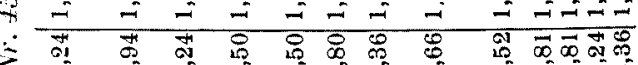

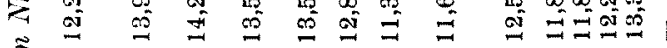
䜦

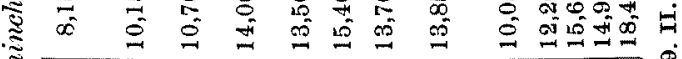
క

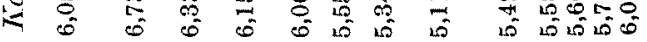

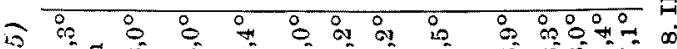

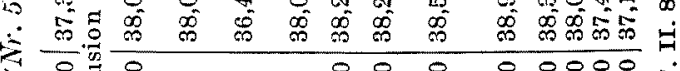
క

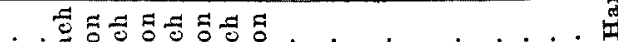

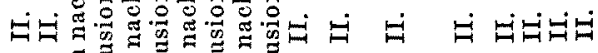

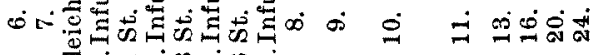

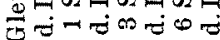



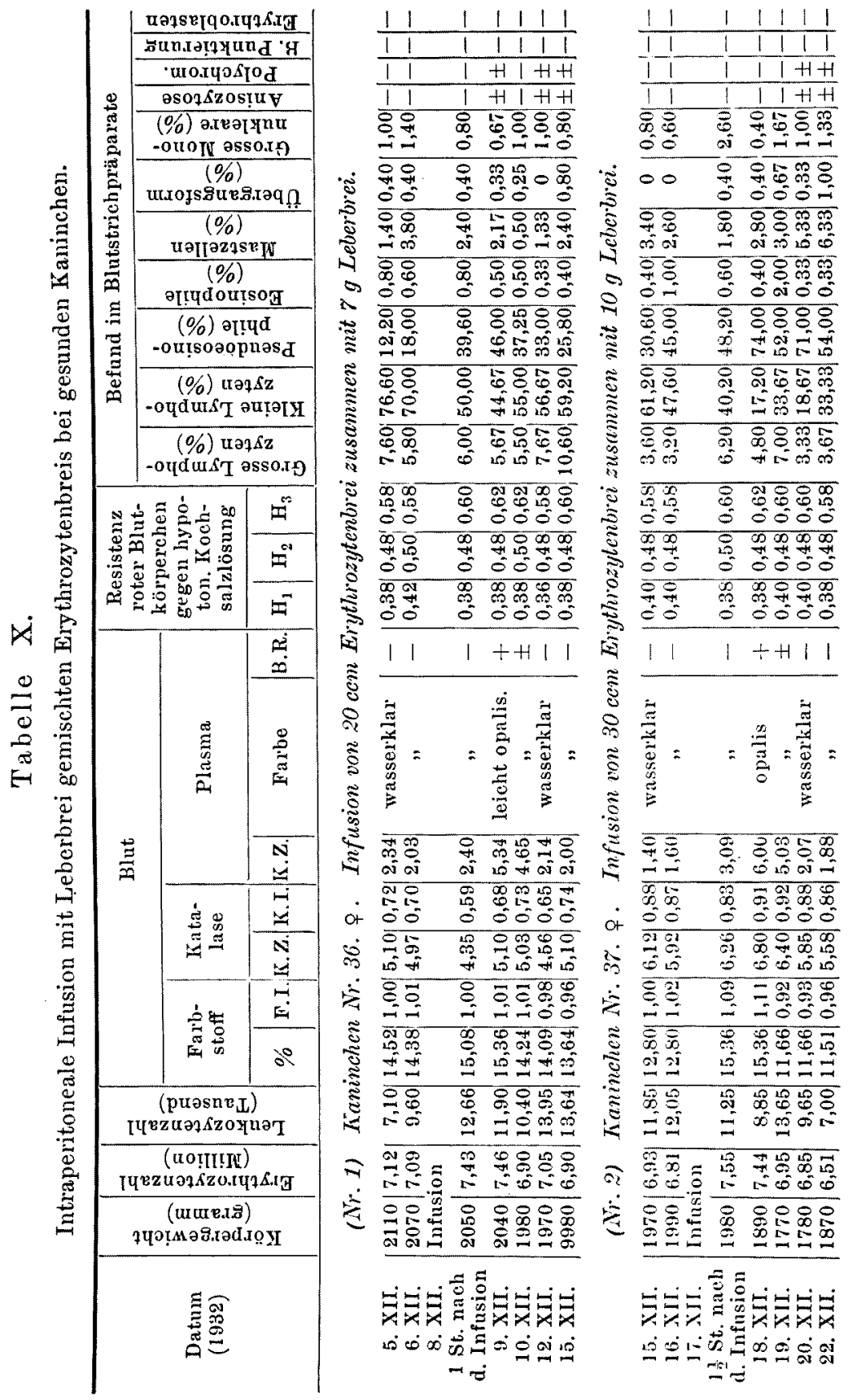

융요의

$\rightarrow$ i 0 ó

88 \& 8888

की

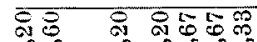

एक

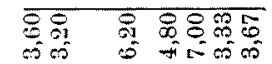

का $8988 \%$

है

क类

$\begin{array}{lll}00 & 0 & 000 \\ 00 & 0 & 000 \%\end{array}$

항 80000

1 $11++11$

a $\mid 1+H 11$

క్

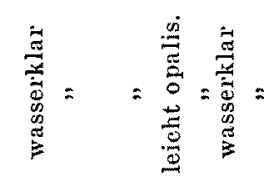

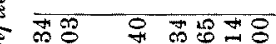

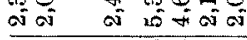
굥 9045 of 50 क 5005

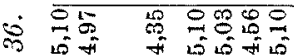

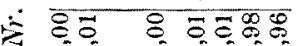

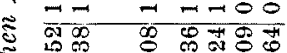
400 \pm \pm 는 융ㅇㅇㅇ요의 $\therefore$ की $=0$ की

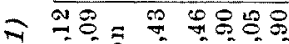

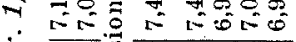

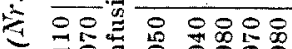

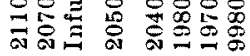

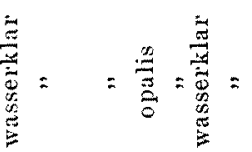

ㅌ․ 8950

कू की

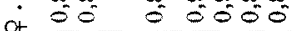

- 명

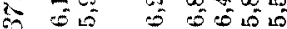

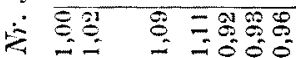

ड 50 क

ô 2 늘

क 2 ब

$= \pm \quad=\infty \mathrm{cos}=$

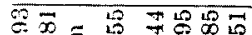

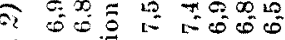

$\doteqdot 8898080$

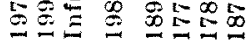

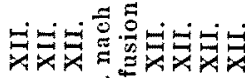

$=\pi$

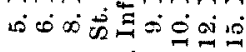

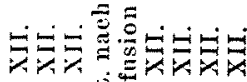

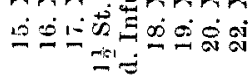



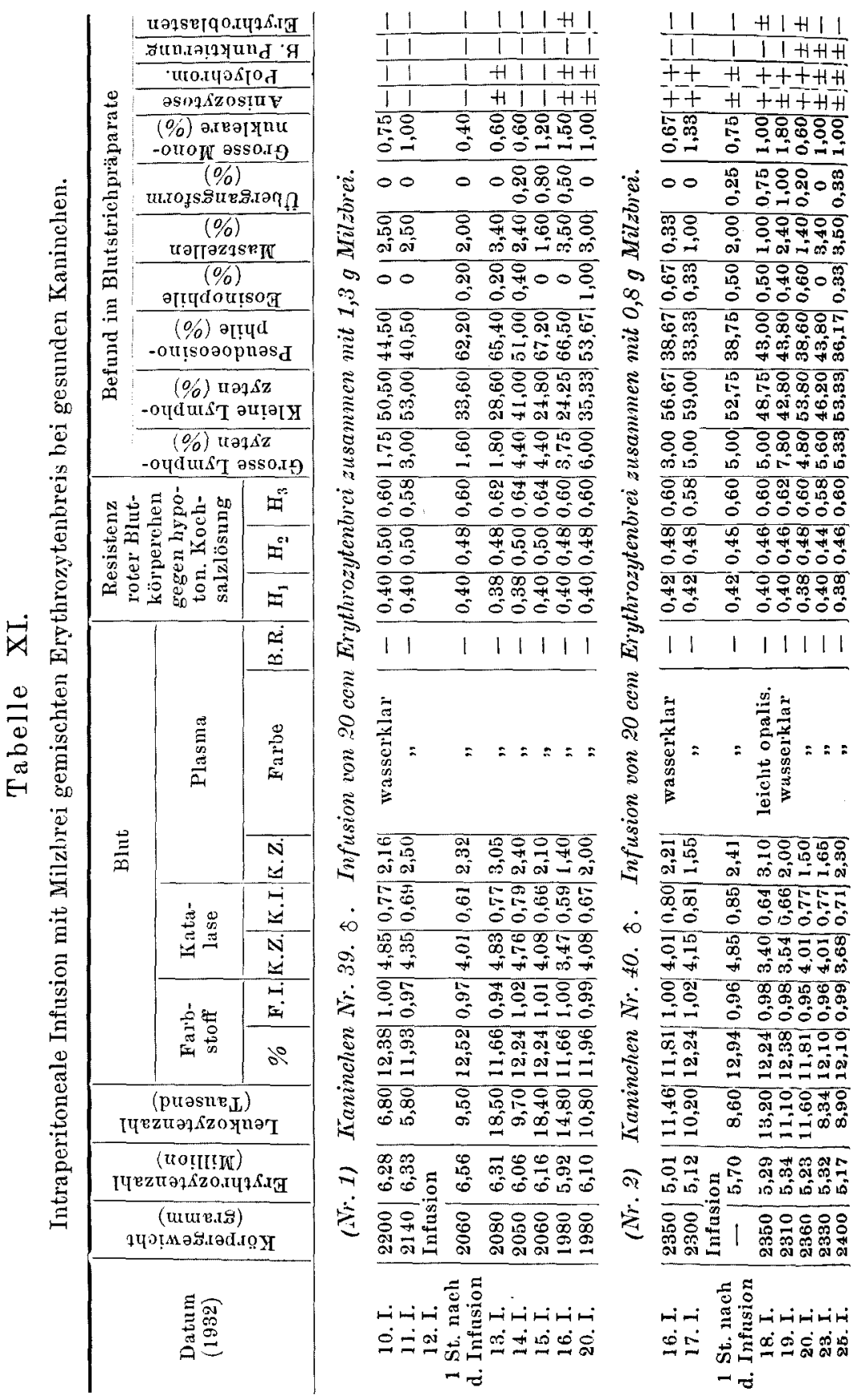


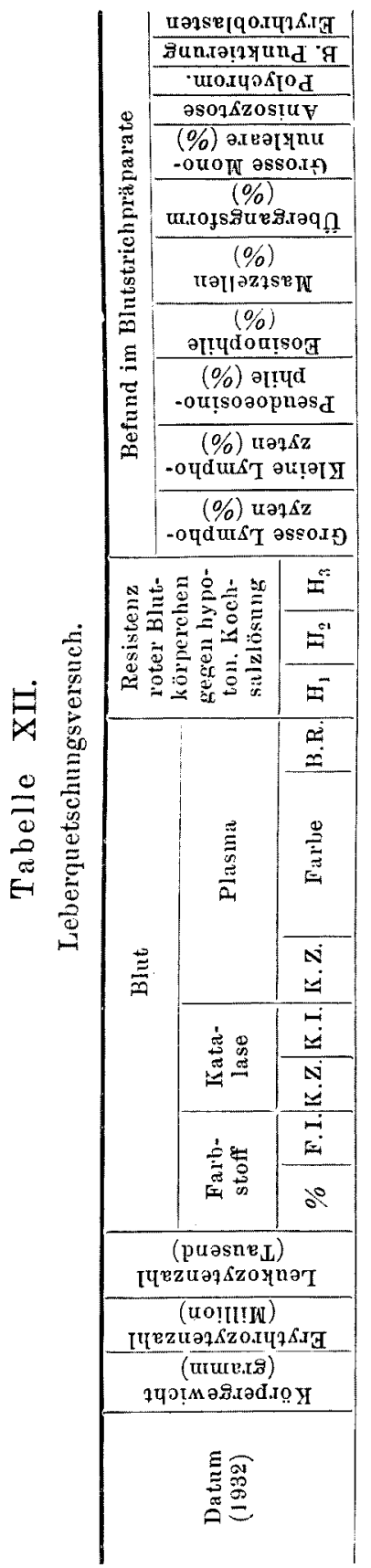

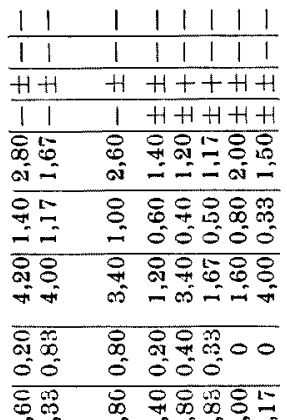

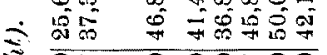
둥 Lิ क

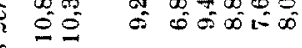
का

今े 央禾 升 50 है की 000 안 엉유용

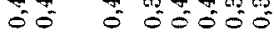
$111+1111$ $\frac{\vec{s}}{\vec{z}}=z====$

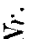

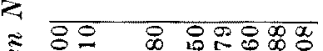
ङ

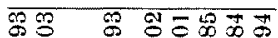
क용

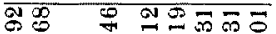

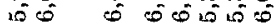

त)

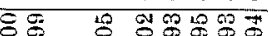
$\doteq$ io $\pi$ nió0 कू

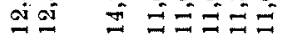

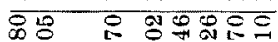
Ei की

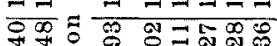
궁 0 $00=\frac{0}{0} 000000$

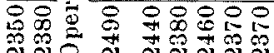

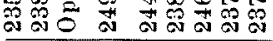

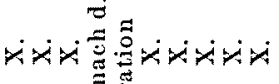
ง

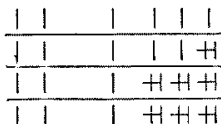

88 ᄋ $10 \% 0$ $0=000=$ 윰유 응 ०० 0 0ं 6ᄋ 8 웅요

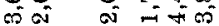

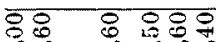
in 0 o $=0$ क융

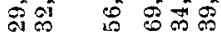

× $8 \%$ ᄋ $8 \%$ 造 की 유 कू 人 $\infty$ क 15.5

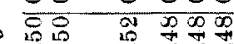
0. 0 o 00 If ता $\infty \infty \infty$ 추

l $1+++1$

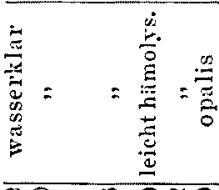

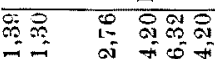
जद 5 की 50 :

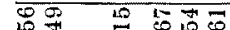
संत न ले ली 요 요용 ๑马 कi को की बi $=$ ल० 8 क

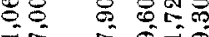
$=$ 厂 응 애웅 की 융 8 용

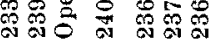

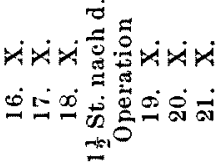



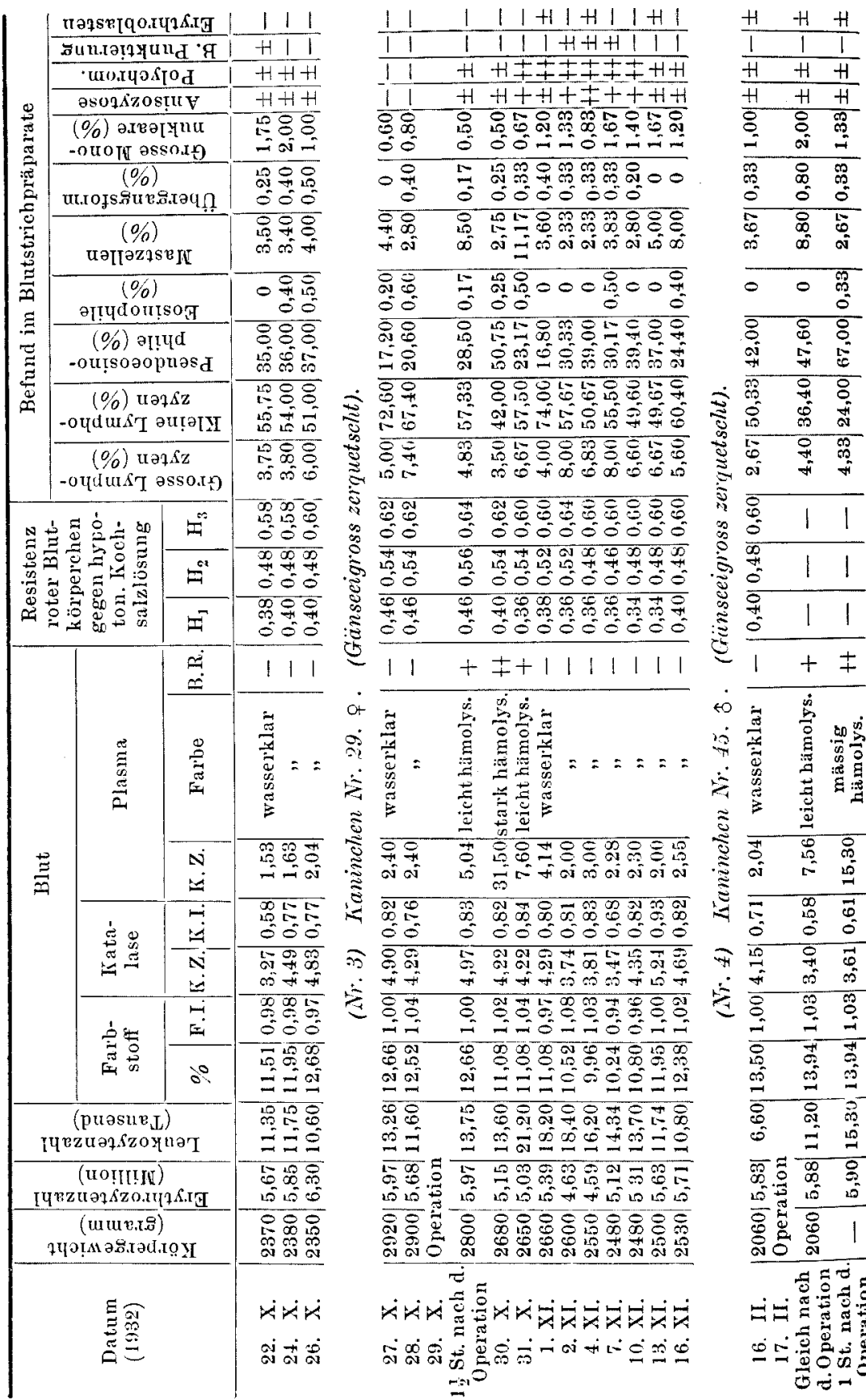

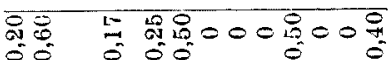

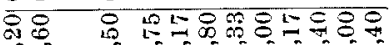

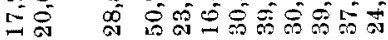
бㅇ

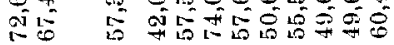
8与 क का

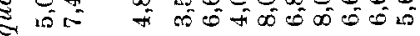

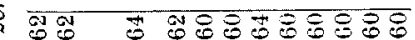

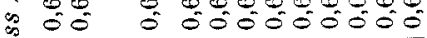

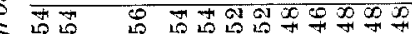
की 0 की की

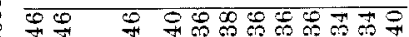

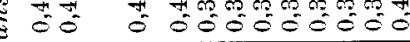

- $\dot{\theta} \dot{\Delta} \dot{0}$

\begin{tabular}{|c|c|}
\hline 0 & 0 \\
\hline 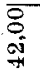 & $\begin{array}{l}8 \\
\Sigma \\
=\end{array}$ \\
\hline 8 & $\begin{array}{l}\text { f } \\
\text { : } \\
0\end{array}$ \\
\hline $\begin{array}{l}\text { T0 } \\
\text { an }\end{array}$ & fi \\
\hline
\end{tabular}

(3)

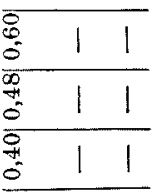

窎

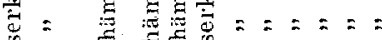

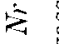

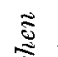

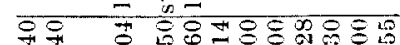

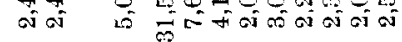

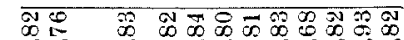
00 0 00000000

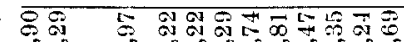

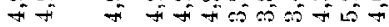

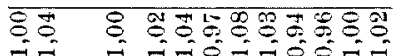
\%

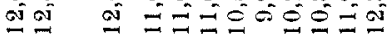

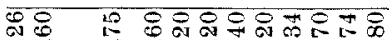

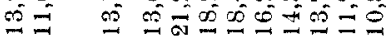

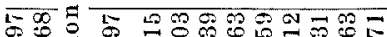

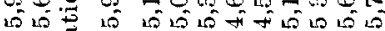

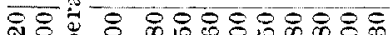

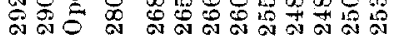

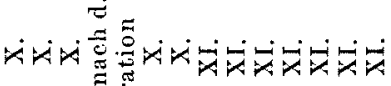

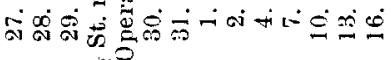

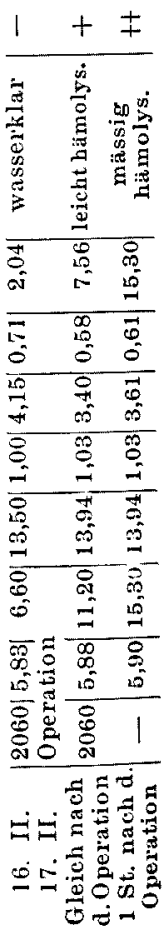




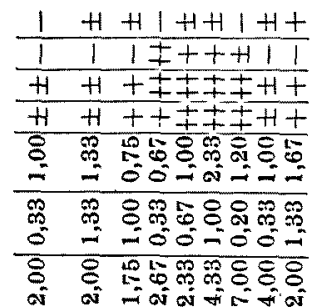

00 का ०ิी0

क क क ल

क

$8 \delta$ a

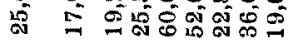

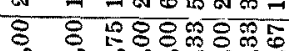

को

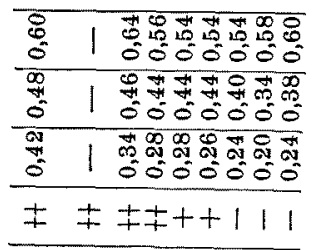

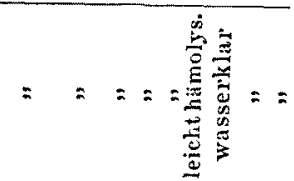

중 웅 8802010

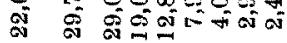

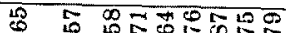

0 0 000000

-

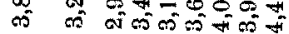

क क की

- 0 0000000

क ज $\mathrm{N}$ क

- as $=000000$

य

$=$ m $-\infty \pm 000$

$\infty \quad \delta=\infty 5 \infty \infty$

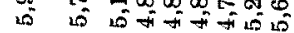

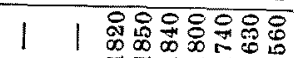

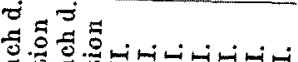

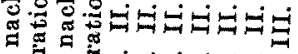

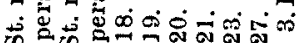

ठ

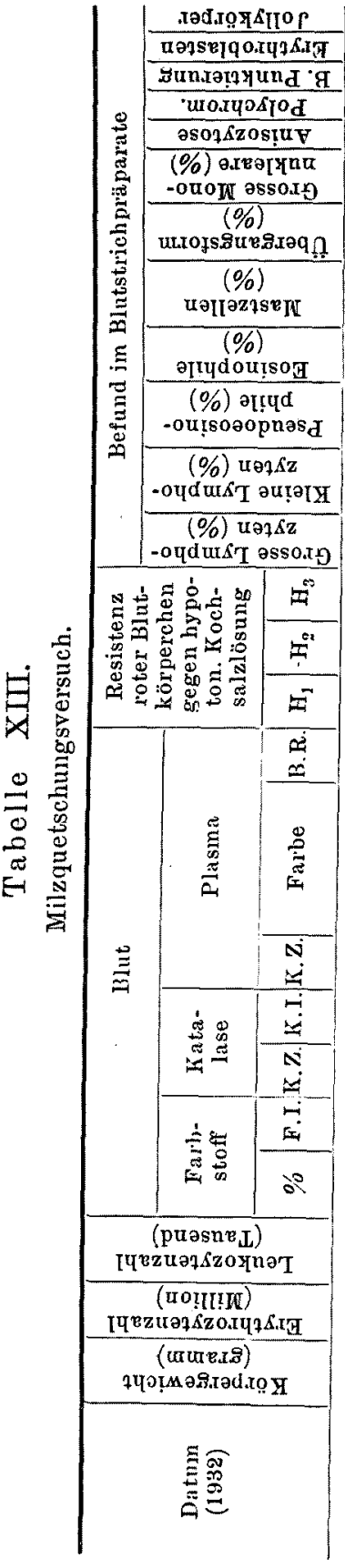

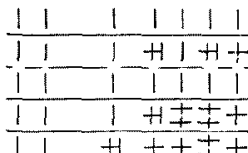
88 9 8808

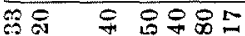
of o : 58 के ल융

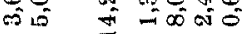

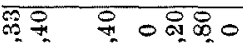
in $\rightarrow$ i 00

व유 8000

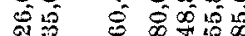

芯

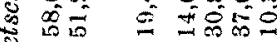

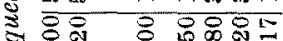

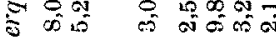
- $8080 \%$ ₹

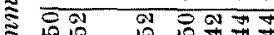
00 o 000 न ग व म000

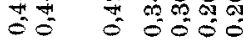
1111111 $\leftrightarrow$

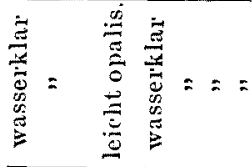

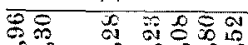
$=-$ को को $=$ 品旦 00 o 0000 $7=000$

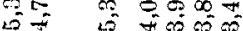
ह

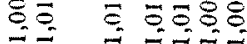
जू बूँ हु 으. 250000 $\Xi \overline{0}$ के क्ष $0 \sigma^{\circ} \approx 000$ एँㄷㅇㅛ $00 \%$ L 요ㅇㅛㅛ

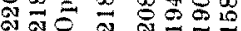

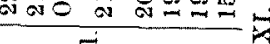

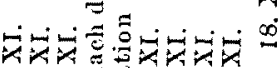

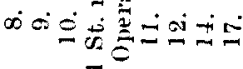




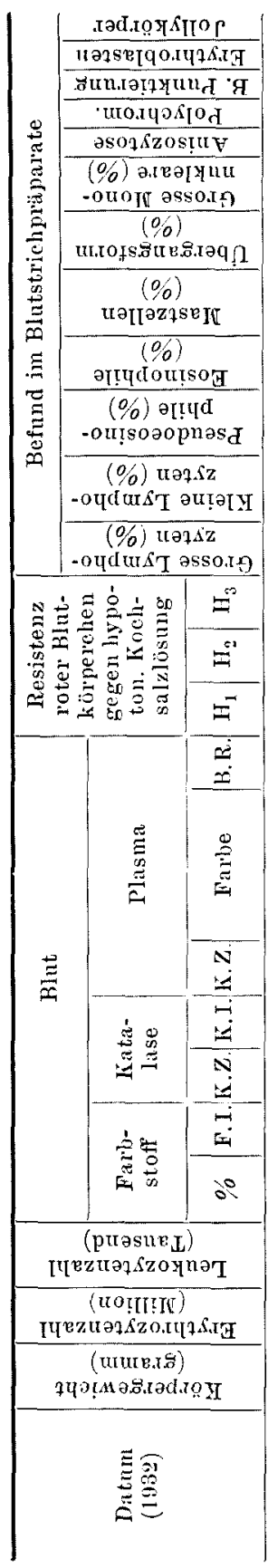

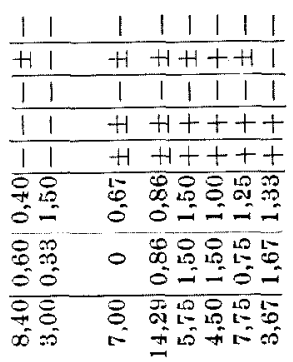

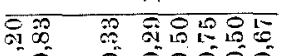

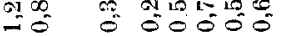

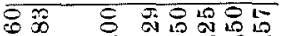
F㶽 बी

$\approx 0180080 \%$ พำ

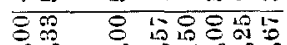
fi 0 की

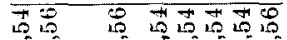
ô के क्ष००0 第 升 $0=0$ 00 050

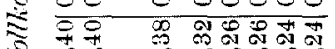
过 की $\therefore 11+1111111$

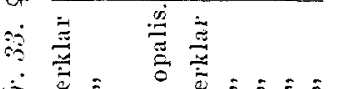

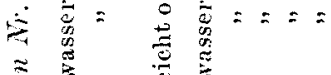
$\underset{\widetilde{3}}{\widetilde{3}}$

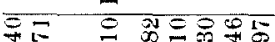

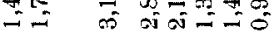
एक ¿o o 00050 ता

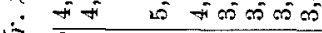
这

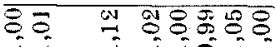

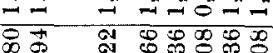

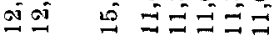

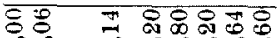

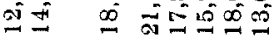

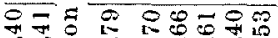

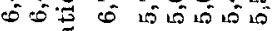

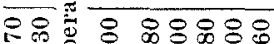

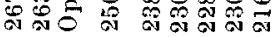

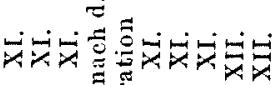

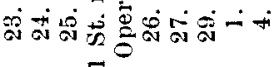

\begin{tabular}{|c|c|}
\hline $\mathrm{H}+\mathrm{H}$ & $\frac{1}{H+H++H \cdot 1} 1 \frac{1}{H+1}$ \\
\hline 1 & 11111111 \\
\hline & $H++H+H++t$ \\
\hline$H$ & $H+H+H+H++$ \\
\hline 总 & 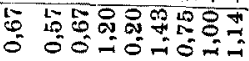 \\
\hline g & 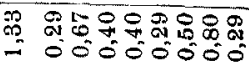 \\
\hline$\infty_{\infty}^{\infty}$ & 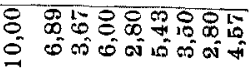 \\
\hline
\end{tabular}

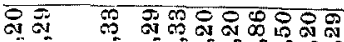
-1 - 0 -

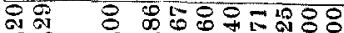

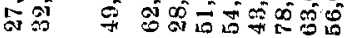
영 5

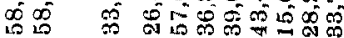
유 8 क

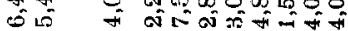
60 $50007015 \%$

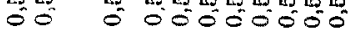

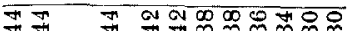

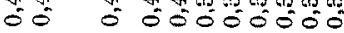
$\infty \%$ क की 0 की l 1 1 1 1 1 1 1 1 1 1

so

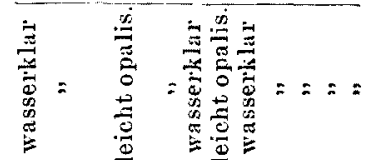
क्ञ की को का का की को OF

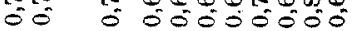

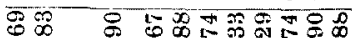

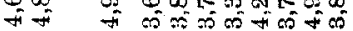
용 $=5=000=0=0$ 苛品 त

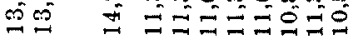
표 \& $8000 \%$ =0 a

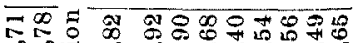
o 0 \%

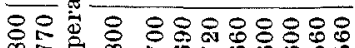

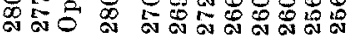

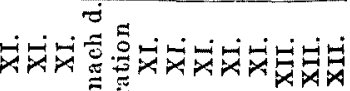

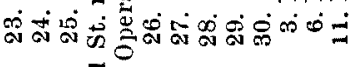

